\title{
Emerging Opportunities in Manufacturing Bulk Soft-Magnetic Alloys for Energy Applications: A Review
}

\author{
ANDREW B. KUSTAS @ ${ }^{1,2}$ DONALD F. SUSAN, ${ }^{1}$ and TODD MONSON ${ }^{1}$ \\ 1.-Sandia National Laboratories, Material, Physical, and Chemical Sciences \\ Center, Albuquerque, NM 87185, USA. 2.—e-mail: akustas@sandia.gov
}

Soft-magnetic alloys exhibit exceptional functional properties that are beneficial for a variety of electromagnetic applications. These alloys are conventionally manufactured into sheet or bar forms using well-established ingot metallurgy practices that involve hot- and cold-working steps. However, recent developments in process metallurgy have unlocked opportunities to directly produce bulk soft-magnetic alloys with improved, and often tailorable, structure-property relationships that are unachievable conventionally. The emergence of unconventional manufacturing routes for soft-magnetic alloys is largely motivated by the need to improve the energy efficiency of electromagnetic devices. In this review, literature that details emerging manufacturing approaches for soft-magnetic alloys is overviewed. This review covers (1) severe plastic deformation, (2) recent advances in melt spinning, (3) powder-based methods, and (4) additive manufacturing. These methods are discussed in comparison with conventional rolling and bar processing. Perspectives and recommended future research directions are also discussed.

\section{INTRODUCTION}

Soft-magnetic alloys containing $\mathrm{Ni}, \mathrm{Fe}$, and/or Co are characterized by exceptional functional properties, including high saturation induction, high permeability, low coercivity, and low core loss, making them ubiquitous in a wide range of electromagnetic devices for power generation and energy conversion. Application examples include transformers, electric motors, and generators. ${ }^{1}$ Historically, these devices have utilized soft-magnetic alloys as the magnetic cores in bar, sheet, plate, and foil forms, which are achieved through conventional multistep processing involving sequential ingot metallurgy practices of (1) casting, (2) iterative thermomechanical forming, and (3) annealing treatments to achieve final desired performance.

While having enabled a wide array of bulk softmagnetic alloy products, these manufacturing steps represent a relatively antiquated approach with limited opportunities to tailor alloy structure-property relationships; For example, conventional Fe-Si

(Received July 21, 2021; accepted October 29, 2021;

published online January 14, 2022) alloys (i.e., electrical steels) are primarily utilized as rolled sheet and are restricted to non-grain-oriented and grain-oriented grades that develop magnetic and mechanical properties based on limited microstructures/textures. ${ }^{2-4}$ Commercial Fe-Co and $\mathrm{Fe}-\mathrm{Ni}$ alloys are likewise restricted by limited product options, ranging from sheet/bar to powder compacts. ${ }^{-7}$ Furthermore, these conventional processes are not always suitable for soft-magnetic alloys due to their limited workability, which originates from solid-state disorder-order phase transformations, thus restricting the alloy design space for electromagnetic applications. ${ }^{1,8-13}$ The typical mitigation tactic for improving the ductility and enabling conventional processing of these alloys is to modify the composition. Drawing back to the FeSi example, laminations with $6.5 \mathrm{wt} . \%$ silicon are promising next-generation alloys for electromagnetic applications. However, conventional processing challenges exist due to the near-zero tensile ductility of the alloy, preventing their widespread commercial adoption. The current solution is to utilize alloys with lower Si content (<4 wt.\%), which can be produced conventionally, despite leading to a drastic reduction in component magnetic performance. ${ }^{11}$ Similarly, binary Fe-Co alloys 
have tensile ductility ranging from $0 \%$ to $4 \%$ strainto-failure. Thus, binary $\mathrm{Fe}-\mathrm{Co}$ is alloyed with ternary additions, e.g., V, Nb, etc., that marginally improve ductility but reduce saturation induction and permeability. ${ }^{14}$

Consequentially, conventional ingot metallurgy practices lead to an inevitable tradeoff in the inversely correlated mechanical and magnetic properties, where routes that improve mechanical properties almost invariably reduce magnetic performance. Notably, these poor mechanical properties are unfavorable for high-performance applications, in particular those encountered in the aerospace industry. ${ }^{7}$ The challenges in fabricating soft-magnetic alloys with improved structure-property relationships have motivated the continued exploration of alternative "unconventional" or emerging manufacturing methods in recent years to overcome these property tradeoffs. These novel methods aim to complement or displace traditional bulk processing methods to enable broader material and electromagnetic component design freedom and enhanced efficiency. Recent estimates of electricity consumption in the USA illustrate the need for improving the energy efficiency of electromagnetic systems, where the industrial sector consumes nearly a third of the total electricity and, of this, at least $65 \%$ is consumed by electric motors/machinery. ${ }^{15,16}$ Modest improvements in the energy efficiency of these devices will also have substantial positive effects on $\mathrm{CO}_{2}$ emissions, where a $1 \%$ improvement would reduce emissions by several million metric tons. ${ }^{15}$

This review covers emerging manufacturing categories of (1) severe plastic deformation, (2) recent advances in melt spinning, (3) powder feedstock development and consolidation methods, and (4) additive manufacturing for processing bulk softmagnetic alloys. Within each category, processing fundamentals are discussed and studies are reviewed that focus on process-structure-properties evolution for a wide array of soft-magnetic alloys, including advanced nanocrystalline/amorphous alloys. General fundamentals of soft-magnetic materials are not reviewed, and the reader is referred to Refs. 1 and 2 for additional details.

\section{CONVENTIONAL PROCESSING METHODS}

This section briefly discusses the fundamentals of conventional metallurgy processes used to produce bulk forms of soft-ferromagnetic alloys, with a particular emphasis on thermomechanical processes utilized for shaping cast ingots/billets into useful products. For a more complete overview of conventional manufacturing methods for bulk softmagnetic alloys, the reader is referred to Refs. 1,2 , 5, 6, 11 and 17 .

\section{Sheet Rolling}

Rolling has long been established as a primary manufacturing route for soft-magnetic alloy sheet and imposes plane-strain deformation, typically through multiple steps of hot/cold reductions of cast ingots/billets, often with intermediate annealing steps, to achieve the final desired sheet/foil thickness and surface quality. ${ }^{18,19}$ While having enabled processing of large volumes of magnetic alloy sheet, rolling has several disadvantages, such as (1) the requirement for multiple processing steps, (2) inhomogeneous deformation, (3) limited control of sheet microstructure, and (4) impracticality for alloys with low material workability. ${ }^{20}$ Notably, materials-related workability challenges are particularly problematic for traditionally brittle soft-magnetic alloys. Rolling is limited in the extent and confinement of deformation-induced heating and hydrostatic pressure during processing, which are important for enhancing the ductility and workability of metals during deformation. ${ }^{18}$ Furthermore, rolling produces "in-plane" crystallographic textures that restrict structure-properties relationships in soft-magnetic alloys, including coercivity, permeability, and core loss.

A notable example highlighting the challenges of sheet rolling of soft-magnetic alloys is electrical steel $(\mathrm{Fe}-\mathrm{Si}$ ) alloys. Hot-rolled sheet products are generally limited to $\sim 4 \mathrm{wt} . \% \mathrm{Si}$ compositions, despite the benefits of increasing the silicon content in iron. Specifically, increasing the silicon content (1) increases the electrical resistivity and permeability and (2) decreases the eddy current losses, magnetostriction, and coercivity, while only resulting in a modest decrease of the saturation magnetization. $^{20-23}$ However, high-Si-content alloys cannot be produced as sheet solely by rolling. Consequently, manufacturers developed a new path to achieve 6.5 wt.\% Si in their electrical steels using a chemical vapor deposition (CVD) process ${ }^{24}$ that can create either (1) a uniform 6.5 wt.\% Si content throughout the sheet thickness or (2) a gradient of silicon content across the sheet thickness, allowing for enhanced performance at higher frequencies. $^{21,25}$ In addition, powder rolling has been proposed as an alternative to conventional sheet production. However, as it only replaces cast ingot with powder as starting material and fundamentally relies on the same mechanics of rolling to consolidate the powder into sheet, it is not discussed further as an unconventional method. ${ }^{26}$

\section{Bar Processing}

Soft-magnetic alloy bars are produced conventionally by bar rolling or gyratory (radial) forging. Starting from a cast ingot, the initial large-diameter billets can be produced by extrusion or forging to provide the initial breakdown of the cast microstructure. In bar rolling, the billets are then passed through a series of grooved rollers to achieve the desired final diameter. ${ }^{27}$ As with sheet forming, the bar rolling process limits the final product to the crystallographic textures common for bar or rod, 
namely a preferred (110) fiber texture along the bar axis for body-centered cubic (BCC) material. Other aspects of the microstructure, such as grain size, are influenced by the final roll pass temperatures and the cooling rate. Similarly, gyratory radial forging processes start with ingot processing and initial hot extrusion or forging. From there, the bars pass through one or more sets of high-speed hammers applying forging deformation in the radial direction while the bar is spinning about its axis. ${ }^{28}$ Through this repeated hammering process at elevated temperature, the bar length increases and the diameter decreases to its desired dimension. With either bar processing method, final soft-magnetic components can be conventionally machined, typically with a final annealing treatment to optimize their softmagnetic performance. Due to the nature of the deformation processes, significant microstructure and property gradients can develop between the outside and the center of the bar, which is a drawback of conventional bar manufacturing methods. $^{29}$

\section{EMERGING AND UNCONVENTIONAL MANUFACTURING METHODS}

This section discusses manufacturing processes that are emerging candidates for fabricating bulk soft-magnetic alloys, with the discussion limited to the processing/forming of bulk material. Thus, processes in the nanoscale regime are not considered. Fundamentals of each processing route are overviewed, and key results from literature are critically reviewed. Recommendations for future work are also provided.

\section{Severe Plastic Deformation}

Severe plastic deformation (SPD) processes have long been explored as advanced techniques for manufacturing nanostructured metals and alloys, initially motivated by opportunities to achieve increased strength, ductility, and toughness. ${ }^{30}$ These methods have become increasingly popular for use on soft-magnetic alloys to achieve unusual combinations of mechanical and magnetic properties. This section reviews SPD processes that have been applied to soft-magnetic alloys.

\section{Hybrid Cutting Extrusion}

Hybrid cutting extrusion (HCE), also called largestrain extrusion machining (LSEM), is an SPD cutting process that imposes large deformation strains to create continuous sheet and foil forms of alloys. Initial work by De Chiffree was motivated by the production of soft metal strips at high speeds. ${ }^{31}$ HCE has since been modified and introduced by researchers at Purdue University as a single-step method for creating continuous high-strength nanostructured alloy sheets/foils ${ }^{32}$ from several materials systems, such as $\mathrm{Mg},{ }^{33,34} \mathrm{Al},{ }^{35,36} \mathrm{Cu},{ }^{37}$ and $\mathrm{Ti}^{38,39} \mathrm{HCE}$ invokes single-step shear-based deformation by peeling away thin cross-sections (i.e., sheets) of material from a workpiece through a sharp, wedge-shaped die consisting of a cutting and constraining tool (Fig. 1). This constraint enables simultaneous cutting-extrusion and prevents material flow on the sheet surfaces with a controlled thickness through selection of a chip thickness ratio $(\lambda)$. Confined simple-shear deformation leads to sheet formation at large strains $(>1)$, high hydrostatic pressures ( $>300 \%$ rolling), and high strain rates $\left(\sim 10^{3} \mathrm{~s}^{-1}\right)$. Sheets can be produced with a range crystallographic textures, the orientation of which can, to a first order, be predicted by the shear zone orientation $\phi^{\prime}=90^{\circ}+\alpha-\phi$, where $\phi=\tan ^{-1}(\cos$ $\alpha /(\lambda-\sin \alpha))$ and $\alpha$ is the cutting tool rake angle. $\mathrm{HCE}$ also results in significant temperature increases during deformation that, combined with the hydrostatic pressure, enables manufacturing of sheet from low-workability alloys, including softmagnetic alloys. ${ }^{20}$

The initial study by Kustas et al. explored HCE processing of a nominal Fe-4 wt.\%Si alloy (warmrolled plate workpiece) and $\mathrm{Fe}-6.5 \mathrm{wt} . \% \mathrm{Si}$ alloy (cylindrical casting). ${ }^{20}$ HCE sheet microstructures were characterized, with an emphasis on the crystallographic texture evolution as a function of deformation and annealing conditions. Select samples were annealed at $700^{\circ} \mathrm{C}$ for $30 \mathrm{~min}$, followed by secondary annealing at $1000^{\circ} \mathrm{C}$ for $5 \mathrm{~h}$ to promote grain growth.

HCE developed shear textures in sheet, defined by two partial $\{110\}$ and $\langle 111\rangle$ fibers that are inclined relative to the sheet length. The angle by which these fibers were inclined was consistent with the theoretical shear plane orientation, $\phi^{\prime}$ for given deformation conditions, only deviating by $\sim 5^{\circ}$ even after recrystallization annealing. The authors stated that the $\{110\}$ fiber results from an alignment of the (110) crystallographic slip planes for BCC Fe-Si at an orientation parallel to the shear/deformation plane. Similarly, the $<111\rangle$ fiber arises from the alignment of the 111 crystallographic directions along the direction of maximum elongation. Figure 2 (top graph) illustrates the near one-to-one correlation between the measured texture inclination angles, taken from the (101) pole figures in Fig. 2a-d, and theoretical expectations from the upper-bound shear-plane model, illustrating the predictive nature of the HCE process for texture design. Notably, the shear-texture character was retained throughout all post-processing steps, suggesting that the as-deformed texture is particularly resilient to post-processing heat treatments, which is unlike rolled electrical steel sheet, where textures are highly influenced by heat treatments. ${ }^{40}$

Conducting a follow-on study, Kustas et al. characterized structure-magnetic property relationships of the Fe-4 wt.\%Si sheet produced using HCE and conventional flat (warm) rolling. ${ }^{41} \mathrm{HCE}$ and rolled sheet were processed to the same 


$$
\lambda=t_{c} / t_{o}
$$

(a)

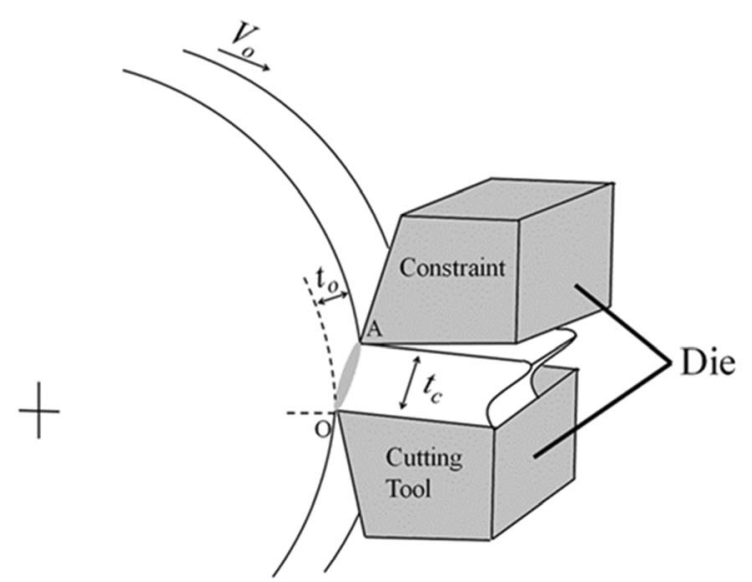

(b)

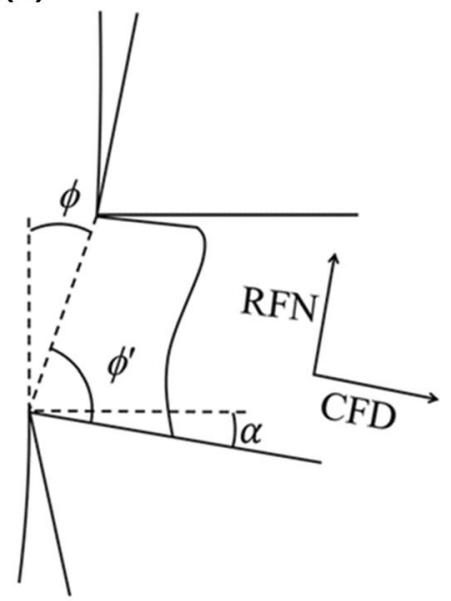

Fig. 1. (a) Rotary configuration of the hybrid cutting extrusion process with the deformation often idealized as a shear plane, as modeled in (b). Reprinted with permission from Springer Nature: Ref. 20-A. B. Kustas, D. Sagapuram, K. P. Trumble, and S. Chandrasekar, Texture Development in High-Silicon Iron Sheet Produced by Simple Shear Deformation, Metall. Mater. Trans. A Phys. Metall. Mater. Sci. 47, (2016).

effective strain, but the latter required preheating at $300^{\circ} \mathrm{C}$ to avoid cracking issues during rolling. The $\mathrm{HCE}$ and rolled sheet specimens were annealed, leading to an average $\sim 25 \mu \mathrm{m}$ grain size. For comparison purposes, a conventionally processed non-grain-oriented (NGO) electrical steel sheet, tradename DI-MAX HF- $10 \mathrm{X}^{42}$ from AK Steel, was characterized, having a composition of $3.3 \mathrm{wt} . \% \mathrm{Si}$, 0.9 wt.\% $\mathrm{Al}$, and bal. Fe with coarser grain size of $\sim$ $150 \mu \mathrm{m}$. The authors found that the rolled and $\mathrm{HCE}$ sheet had comparable properties in terms of the maximum permeability (1560 versus 1698), fullfield induction (1.75 $\mathrm{T}$ versus $1.58 \mathrm{~T}$ ), and coercivity $(153 \mathrm{~A} / \mathrm{m}$ versus $111 \mathrm{~A} / \mathrm{m})$. However, both laboratory-produced products were magnetically harder than the commercial NGO sheet, which had permeability of 10,900 , full-field induction of $1.92 \mathrm{~T}$ and coercivity of $29 \mathrm{~A} / \mathrm{m}$. It was proposed that these differences in the properties resulted from the larger grain size of the NGO sheet $(150 \mu \mathrm{m}$ versus $25 \mu \mathrm{m}$ ) and the order-of-magnitude lower $\mathrm{C}$ and $\mathrm{S}$ impurity content.

A final study by Kustas et al. compared the workability of high-Si-content electrical steels during rolling and HCE processing. ${ }^{43}$ The same 4 wt. $\%$ $\mathrm{Si}$ and $6.5 \mathrm{wt} \% \mathrm{Si}$ alloys were used as starting materials. Rolling and HCE experiments were conducted as a function of workpiece preheat temperature, with strain-to-failure determined by the presence of through-thickness cracking. Flat sheet rolling required preheating of both alloys to enable any appreciable amount of plastic deformation through the mill without cracking, especially for the Fe-6.5 wt.\% Si alloy. By comparison, HCE required no preheating of either alloy to enable continuous sheet production. Thus, HCE was deemed a far more favorable approach to manufacturing sheet from low-workability $\mathrm{Fe}-\mathrm{Si}$ magnetic alloys.

Overall, the principal advantage of HCE has been in demonstrating processing of continuous $\mathrm{Fe}-\mathrm{Si}$ sheet at high Si compositions (e.g., 6.5 wt.\%), known for having exceptional soft-magnetic properties. Thus, HCE is a viable single-step alternative for continuous soft-magnetic alloy sheet processing. There are opportunities for continuing the exploration of HCE for soft-magnetic alloy sheet. Among the most appealing prospects is processing sheet from an expanded set of soft-magnetic alloys, e.g., the $\mathrm{Fe}-\mathrm{Ni}$ and $\mathrm{Fe}-\mathrm{Co}$ systems. Additionally, optimization of structure-magnetic property relationships through texture and microstructure control remains a promising approach for tailoring magnetic properties in sheet beyond what is possible through rolling. For example, optimization of the shear-texture inclination could enable new magnetic core laminates for motors and transformers with ultrahigh efficiency and uniquely anisotropic properties. Finally, mechanical properties of the soft-magnetic alloy sheets need to be characterized, as HCE has strong potential to improve the mechanical performance of laminated magnetic cores due to the unique shear textures that develop in sheet. Indeed, such improvements in mechanical properties have been noted for other traditionally brittle alloys. ${ }^{38}$

\section{Equal-Channel Angular Extrusion}

Equal-channel angular extrusion/pressing (ECAE/ECAP) is an SPD process used to refine the 


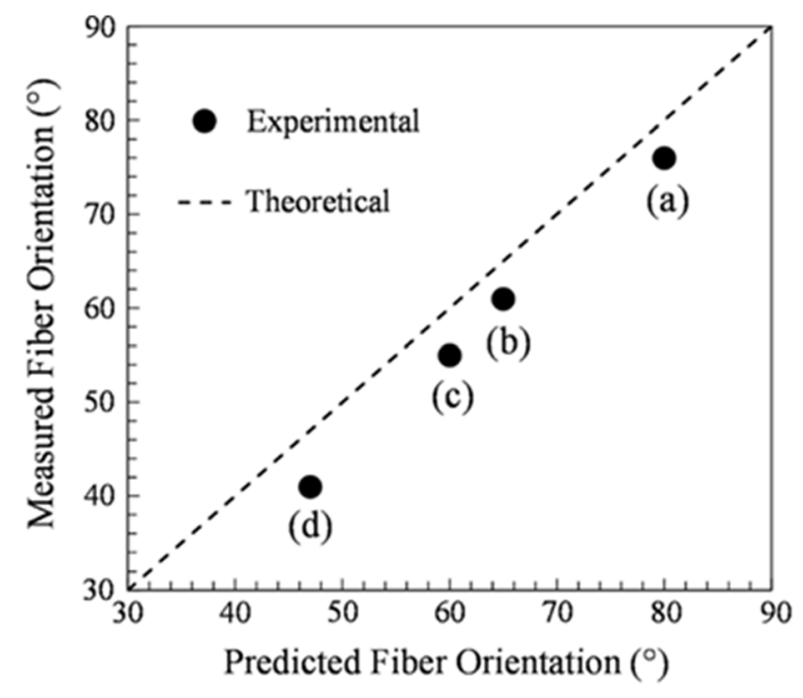

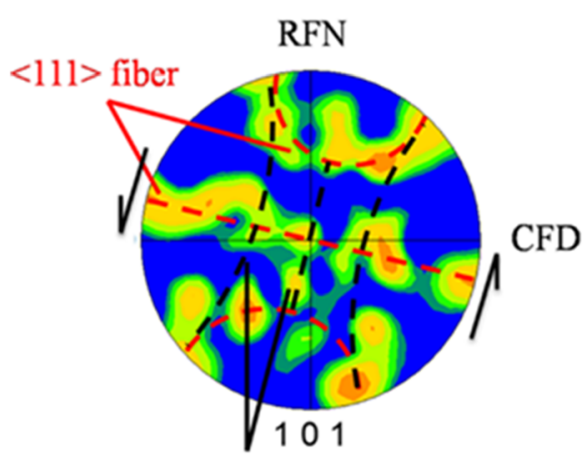

$\{110\}$ fiber

(a)

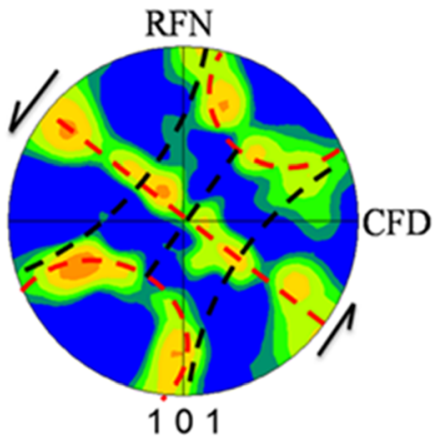

(c)

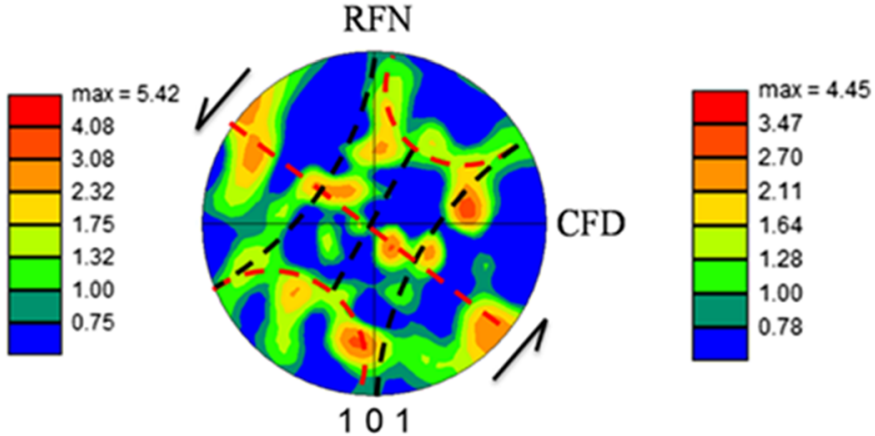

(b)
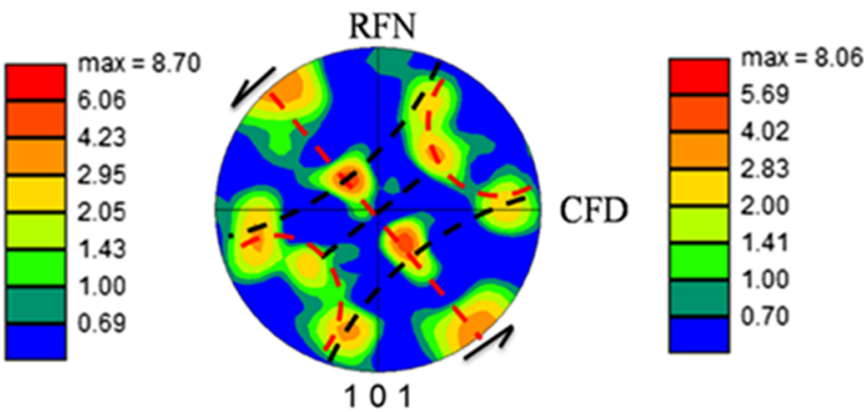

(d)

Fig. 2. Plot of measured texture fiber inclination angles from the (101) pole figures (a-d) below, showing near one-to-one correlation between experiments and upper bound model predictions. Reprinted with permission from Springer Nature: Ref. 20-A. B. Kustas, D. Sagapuram, K. P. Trumble, and S. Chandrasekar, Texture Development in High-Silicon Iron Sheet Produced by Simple Shear Deformation, Metall. Mater. Trans. A Phys. Metall. Mater. Sci. 47, (2016).

microstructure and increase the strength of bulk rod or bar products, although it can be applied to plate as well. First developed in the 1970s by Segal, the process involves extruding a billet through a die with diameter $d$ and angle $\Phi$, usually $90^{\circ}$ or $120^{\circ}$, to impart extreme shear deformation and corresponding microstructural refinement ${ }^{44,45}$ (Fig. 3). The magnitude of the strain and corresponding strain path imposed within a single pass is proportional to the die angle $(\Phi)$. Due to the severe deformation, ECAE delivers properties that are unattainable from conventional bar processing and without a change in cross-section; i.e., it can produce highstrength material in bulk/thick sections. Microstructures and crystallographic textures can be tailored by changing the total number of deformation passes and directions of shear by axial 


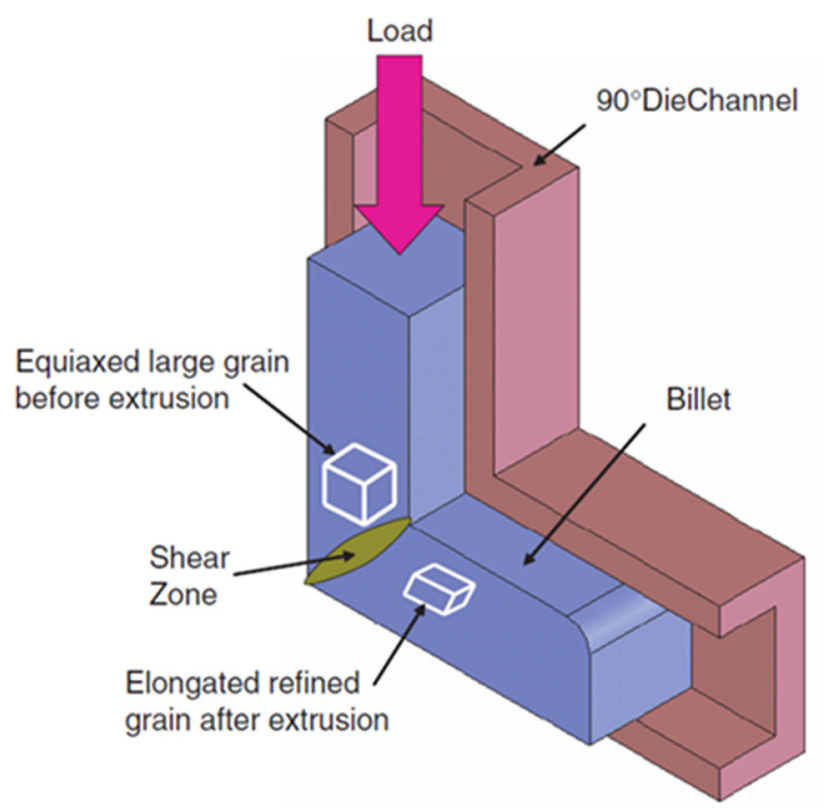

Fig. 3. Schematic detailing the equal-channel angular extrusion process. Reprinted with permission from Taylor \& Francis Ltd: Ref. 46-I. Karaman, A. V. Kulkarni, and Z. P. Luo, Transformation behaviour and unusual twinning in a NiTi shape memory alloy ausformed using equal channel angular extrusion, Philos. Mag. 85, 1729 (2005).

rotation of the billet between passes, designated as different processing routes. ${ }^{44}$

Application of ECAE to Fe-Co-based soft-magnetic alloys was first proposed in a patent by Gigliotti et al. and included claims for various ternary alloy additions to binary $\mathrm{Fe}-\mathrm{Co}^{47}$ With ECAE, yield strength and, in some cases, ductility were increased through the Hall-Petch effect. However, reduced grain size generally decreases permeability, increases coercivity, and increases core loss. Indeed, Weißner and coworkers used ECAE to magnetically harden pure $\mathrm{Fe}$ and $\mathrm{Fe}-17 \mathrm{Co}$ alloys. ${ }^{48}$ With increased strain through successive ECAE passes, the coercivity increased accordingly, by $340 \%$ for pure $\mathrm{Fe}$ and $480 \%$ for the Fe-Co alloy. As discussed further below, combinations of ECAE processing and post-ECAE annealing can tailor mechanical and magnetic properties, which may be desired for high-performance applications.

Korshunov et al. observed similar behavior in Fe27 wt.\% Co alloy, also known as Hiperco 27. ${ }^{49,50}$ With up to 16 passes of ECAP, significant microstructural refinement was observed along with magnetic hardening (Fig. 4). Korshunov also investigated post-ECAP annealing treatments to regain soft-magnetic properties. For example, with post-ECAP annealing at $770^{\circ} \mathrm{C}$, the alloy coercivity decreased by $\sim 40 \%$. Another study, by $\mathrm{Wu}$ and coworkers, applied ECAP to Fe-42 wt.\%Co- 4 wt.\%V alloy with four passes of route A (with no axial rotation between passes). ${ }^{51,52}$ Following cold rolling, the fraction of high-angle grain boundaries increased. Subsequent heat treatment produced (a)

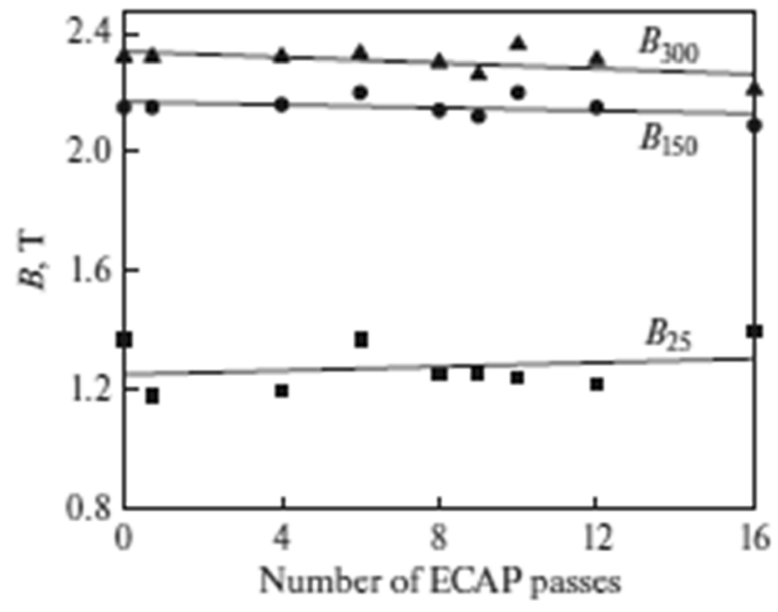

(b)

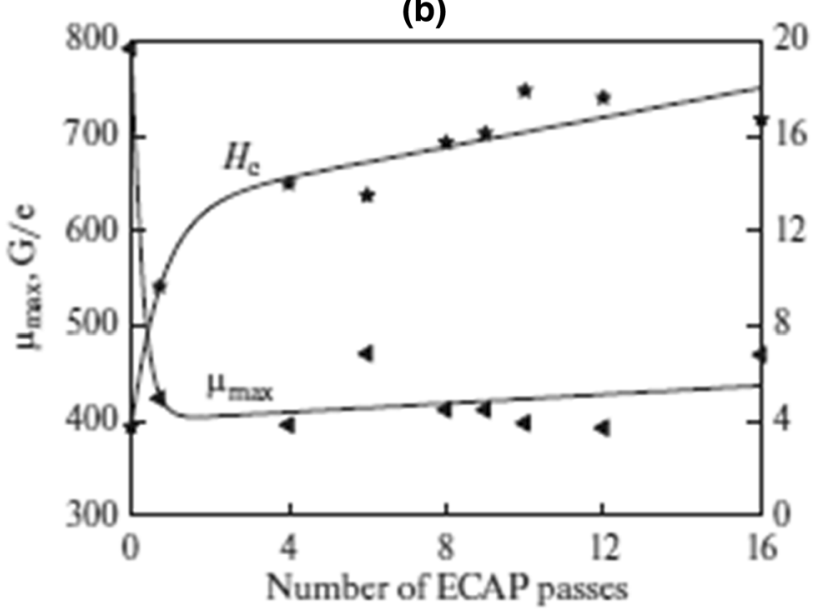

Fig. 4. Magnetic hardening of Hiperco 27 following increasing ECAP deformation, showing gradually decreasing magnetic induction (a) and permeability (b), with increasing coercivity (b). Reprinted with permission fromn Spring Nature: Ref. 49-A. I. Korshunov, N. I. Osipova, A. M. Olenin, Y. N. Pigarev, and O. V. Kulakova, Effect of Equal Channel Angular Pressing and Subsequent Annealing on Magneic Properties of a Soft Magnetic Fe-Co Alloy, Phys. Met. Metallogr. 119, 448 (2018).

nanosized precipitates at subgrain boundaries and within parent grains.

In addition to the studies by Weißner, Korshunov, and $\mathrm{Wu}$ on low-cobalt alloys, recent investigations by Susan and Kustas et al. were performed on $49 \mathrm{Fe}-$ $49 \mathrm{Co}-2 \mathrm{~V}$ alloy, known commercially as Hiperco $50 A .{ }^{29,53-55}$ Unlike low-cobalt alloys, Fe-Co compositions close to $50 \mathrm{Fe}-50 \mathrm{Co}$ are ordered intermetallic alloys with low ductility at room temperature. Therefore, ECAE processing was performed at high temperatures in the disordered BCC state (above $730^{\circ} \mathrm{C}$ ) to preclude widespread cracking during extrusion. Figure 5 displays the increased strength achieved through multipass ECAE of $49 \mathrm{Fe}-49 \mathrm{Co}-2 \mathrm{~V}$ compared with conventionally processed bar material. ${ }^{29}$ Significant improvements in ductility were also realized, possibly due to retention of the disordered BCC crystal structure after quenching 


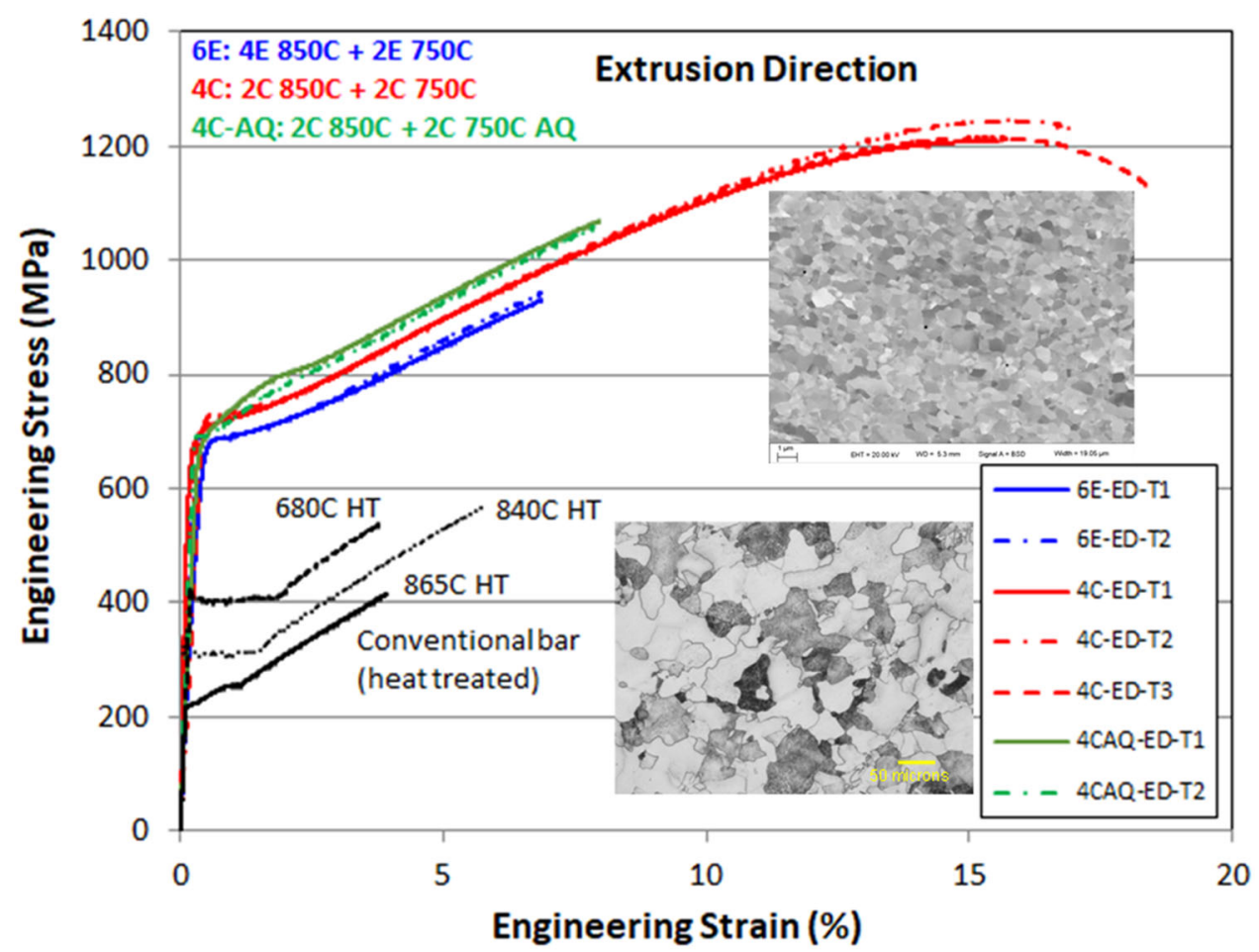

Fig. 5. Stress-strain curves from as-ECAEed material compared with conventionally processed bar of FeCo-2V. Note that the scale of the micrographs differs by approximately 50 times. Reprinted with permission from Spring Nature: Ref. 29—D. F. Susan, T. Jozaghi, I. Karaman, and J. M. Rodelas, Equal channel angular extrusion for bulk processing of Fe-Co-2V soft magnetic alloys, part I: Processing and mechanical properties, J. Mater. Res. 33, 2176 (2018).

from the ECAE temperature. Ductility improvement may also be from slip refinement or slip dispersion, whereby dislocation pileups and crack initiation at grain boundaries are avoided by dispersing slip via fine grains/subgrains, as discussed by George et al. and others. ${ }^{29,53,54,56-59}$ The refined ECAE billet microstructure is also shown in Fig. 5 for reference. Grain size of typical conventional wrought bar is $25 \mu \mathrm{m}$ to $75 \mu \mathrm{m}$, whereas for ECAEprocessed $\mathrm{FeCo}-2 \mathrm{~V}$ it was approximately $1 \mu \mathrm{m}$ to $3 \mu \mathrm{m}$.

The ECAE process also imparts uniform strain across the billet during extrusion, as opposed to conventional bar rolling or forging, wherein deformation and microstructure gradients develop from the center to the edge of the bar. Thus, the ECAE microstructure can help ensure uniform magnetic and mechanical properties, while creating a crystallographic texture that differs from conventionally processed bar and sheet. For FeCo-based alloys and other BCC metals, ECAE generates a texture with dual partial $\{110\}$ and $<111\rangle$ fibers that are inclined relative to the bar length, similar to the texture found in HCE-processed $\mathrm{Fe}-\mathrm{Si}$ alloy sheets. $^{20,44,53}$ This shear texture is also retained after post-ECAE annealing. Kustas et al. suggested that this texture, along with microstructure uniformity, could help explain the slightly better softmagnetic performance observed for post-ECAE annealed material compared with conventionally processed bar. ${ }^{53}$

In the most recent $49 \mathrm{Fe}-49 \mathrm{Co}-2 \mathrm{~V}$ work, postECAE annealing was investigated in more detail to define the tradeoff space between mechanical properties and soft-magnetic performance. ${ }^{54}$ The asECAE condition produces a harder magnetic response, while post-ECAE annealing at increasing temperatures steadily recovered the soft-magnetic performance, until the behavior reverted to that of conventional bar or better. Therefore, through postECAE annealing, one can begin to tailor the desired combination of magnetic and mechanical properties in bar. Using coercivity as a measure of softmagnetic performance, annealing effects are summarized in Fig. 6. As-ECAE material and postECAE heat treatments can produce a wide range of grain sizes and soft-magnetic behavior, as well as exhibiting some of the lowest coercivities reported for FeCo-2V. ${ }^{54,60-64}$

Overall, ECAE paired with post-processing heat treatments offers unique opportunities to tailor mechanical-magnetic property relationships in bulk soft-magnetic alloy bar that are unachievable with conventional processing. Similar opportunities for optimizing property tradeoffs exist for other softmagnetic alloys and are suggested future research directions. Additionally, given the unique shear textures, it is recommended that future studies evaluate the extent of anisotropy in properties 


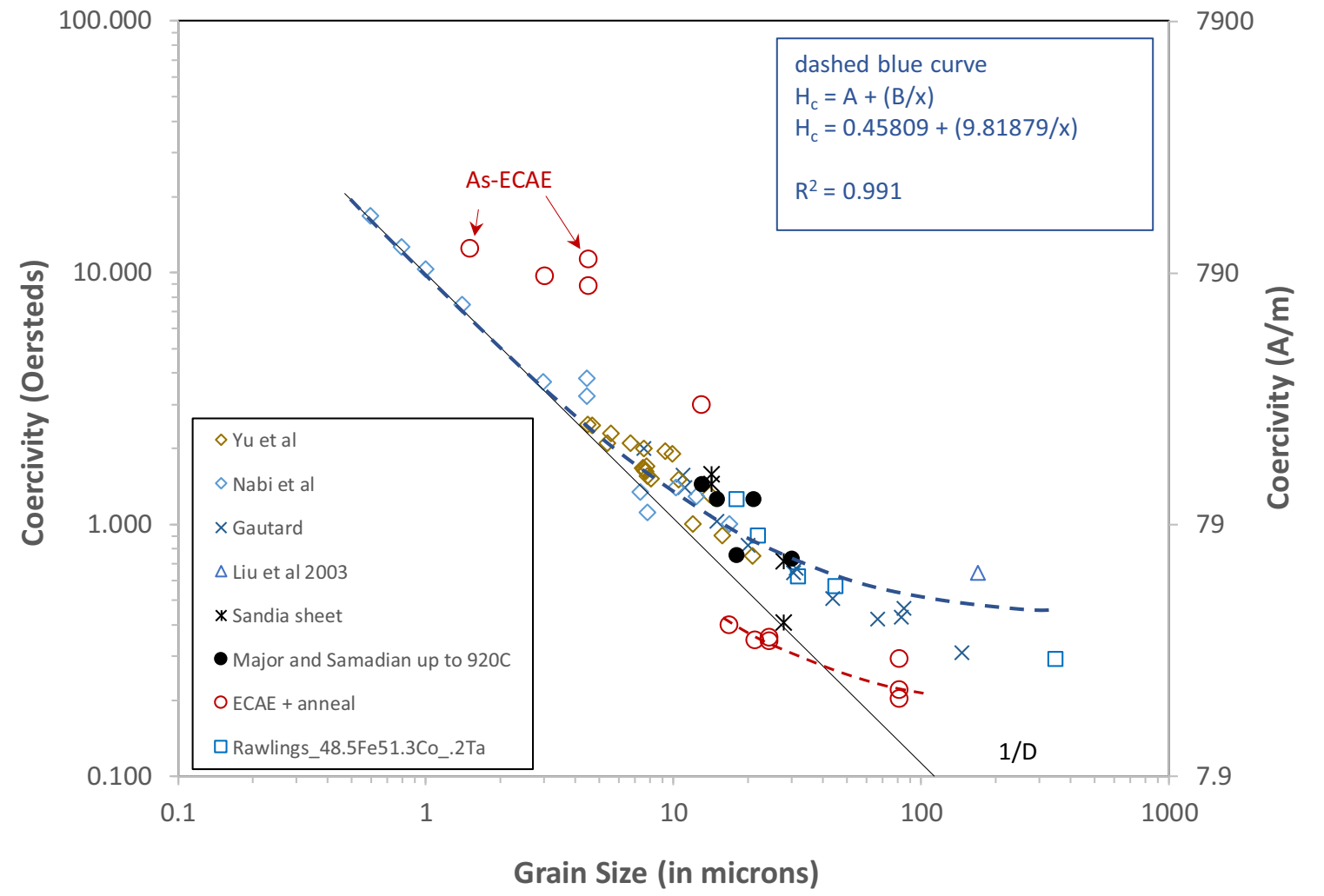

Fig. 6. Relationship of magnetic coercivity to grain size for FeCo-2V processed by ECAE or cold working of sheet with various heat treatments. Reprinted with permission from Spring Nature: Ref. 54-D. F. Susan, A. B. Kustas, R. A. Kellogg, J. D. Carroll, J. R. Michael, and I. Karaman, The Effects of Annealing After Equal Channel Angular Extrusion (ECAE) on Mechanical and Magnetic Properties of 49Fe-49Co-2V Alloy, Metall. Mater. Trans. A In Press (2021).

toward designing textures for specific applications and magnetic flux distributions.

\section{High-Pressure Torsion}

High-pressure torsion (HPT), another SPD process, was originally motivated by the prospect of achieving high-strength alloys. With origins from the seminal work of Bridgman, ${ }^{65,66}$ HPT imposes large deformation strains through the simultaneous application of large compressive $(P)$ and torsional stresses (Fig. 7). Disc-shaped ingots are placed between two large anvils/dies, which define and constrain the deformation zone during processing. Longitudinal compressive stresses are applied via the dies, and incremental torsional straining is imposed via rotation of one die while the adjoining die remains stationary. Plastic deformation occurs from the imposed compressive stresses and surface frictional forces during anvil rotations, leading to large shear strains under quasi-hydrostatic pressure. Like ECAE, the extent of plastic deformation/ strain is controlled by the total number of deformation steps (i.e., anvil rotations, proportional to $\theta$ ) and the extent of compression (change in $h$ ). However, the effective strains imposed during HPT are also a function of the workpiece size (disc radius, $r$ ), increasing from the disc center (near-zero strain) radially outward toward the workpiece edges. This

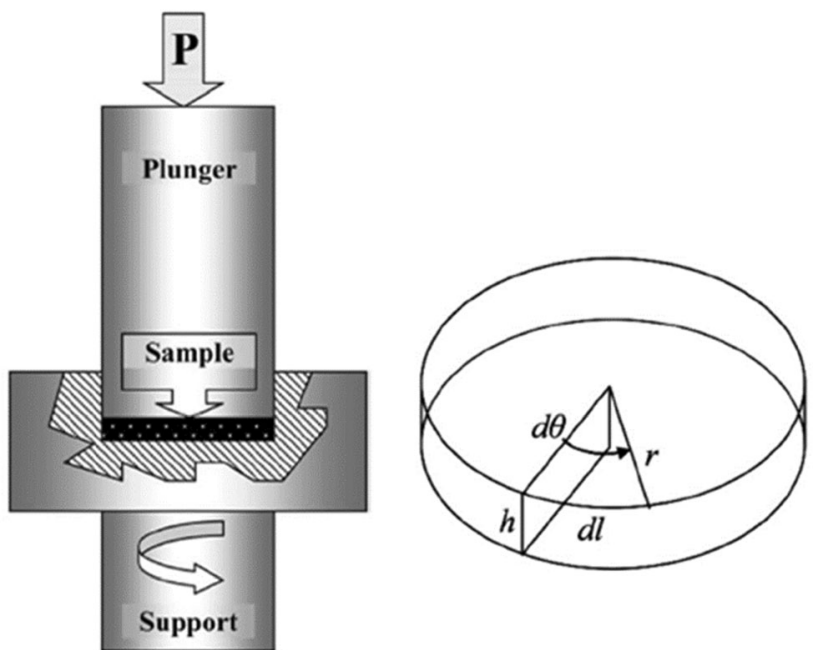

Fig. 7. High-pressure torsion processing schematic. Reprinted with permission from Elsevier: Ref. 66-A. P. Zhilyaev and T. G. Langdon, Using high-pressure torsion for metal processing: Fundamentals and applications, Prog. Mater. Sci. 53, 893 (2008).

strain gradient manifests from differences in the extent of frictional sliding along the workpiece diameter and can have drastic effects on the local material structure-property relationships.

HPT is among the most extensively evaluated SPD processes for producing bulk soft-magnetic 
alloy disc samples. Supplementary Table S1 summarizes key findings from these studies. An early study by Vorhauer et al. ${ }^{67}$ examined soft-magnetic alloys of an Fe-Co steel subjected to HPT deformation at $293 \mathrm{~K}$ to $723 \mathrm{~K}$, which resulted in substantial grain size refinement of the initial workpiece microstructure into the submicron regime. Notably, as-HPT samples possessed $\sim 35 \%$ higher full-field induction compared with the initial workpiece, with data showing a general increasing trend for induction with decreasing grain size until $\sim 100 \mathrm{~nm}$, below which induction decreased. Coercivity exhibited a similar grain-size-dependent relationship.

Scheriau et al. conducted a pair of studies, first focused on HPT processing of $\mathrm{Fe}-3$ wt.\% $\mathrm{Si}$, P800, and Mumetal. ${ }^{68,69}$ Workpieces were deformed at $77 \mathrm{~K}$ and $298 \mathrm{~K}$. Ambient processing temperature resulted in similarly refined equiaxed grain structures to that reported by Vorhauer et al., ${ }^{67}$ while the $77 \mathrm{~K}$ condition promoted a further reduced grain size with elongated morphologies aligned with the maximum shear direction. After deformation, induction values decreased for both P800 and FeSi, with the most dramatic decrease occurring for specimens deformed at $77 \mathrm{~K}$. Interestingly, Mumetal induction values were relatively unchanged following deformation and even increased following HPT at $293 \mathrm{~K}$.

Their second study provided a comprehensive evaluation of HPT of magnetic alloys, including pure $\mathrm{Fe}$ and $\mathrm{Ni}, \mathrm{Fe}-3$ wt. $\% \mathrm{Si}, \mathrm{Fe}-6.5$ wt. $\% \mathrm{Si}$, and $\mathrm{Fe}-$ $17 \mathrm{wt} . \% \mathrm{Co},{ }^{69}$ processed at cryogenic $(77 \mathrm{~K})$, ambient $(298 \mathrm{~K})$, and elevated $\left(0.4 T_{\text {hom }}\right)$ temperatures. HPT processing resulted in similar microstructures as described in their earlier publication, and specimens exhibited a monotonic decrease in hardness with increased HPT temperature, ranging from $225 \mathrm{HV}$ to $750 \mathrm{HV}$, depending on alloy and processing conditions. Unalloyed materials, e.g., pure Fe, remained mechanically softest across all processing conditions, while $\mathrm{Fe}-6.5$ wt.\% Si alloy exhibited the overall highest hardness. Quasistatic and frequency-dependent magnetic properties were characterized (up to $1000 \mathrm{~Hz}$, Fig. 8). Fe-6.5 wt.\%Si alloy exhibited the lowest coercivity as a function of frequency and grain size. Coercivity increased with microstructure refinement until a grain size of $\sim$ $100 \mathrm{~nm}$, below which it decreased rapidly, as predicted by Herzer. ${ }^{70}$

Glezer et al. published a series of papers that explored HPT processing of various soft-magnetic alloys, ${ }^{71-76}$ including (1) $\mathrm{B}_{10} \mathrm{Co}_{15} \mathrm{Fe}_{29} \mathrm{Ni}_{44} \mathrm{Si}_{2}$ (alloy 1), (2) $\mathrm{B}_{9} \mathrm{Cu}_{1} \mathrm{Fe}_{74} \mathrm{Nb}_{3} \mathrm{Si}_{13} \quad$ (Finemet), (3) $\mathrm{B}_{17.5} \mathrm{Fe}_{57.5} \mathrm{Ni}_{25}$ (alloy 2A), (4) $\mathrm{B}_{17.5} \mathrm{Fe}_{49.5} \mathrm{Ni}_{33}$ (alloy 2B), (5) $\mathrm{B}_{15} \mathrm{Fe}_{70} \mathrm{Cr}_{15}$ (alloy 3), (6) $\mathrm{Fe}-24$ at.\%Al, (7) $(\mathrm{FeCo})_{100-x}-\mathrm{V}_{x}$ alloys $(X=0,1.5,3,4.5$, and 6$)$, and (8) Fe-50Co.

Their first study examined HPT using amorphous magnetic ribbons as feedstock, ${ }^{71}$ with magnetic properties determined for samples following HPT at $77 \mathrm{~K}$ and $293 \mathrm{~K}$. Some samples were heat-treated to crystallize the material after deformation. Alloy 1 exhibited a monotonically increasing full-field induction for several deformation steps at $77 \mathrm{~K}$, after which the value remained unchanged upon further deformation. When deformed at $293 \mathrm{~K}$, in both the initial amorphous and post-crystallization states, the induction peaked after a single revolution before decreasing to a relatively steady-state value. Generally, induction values were larger for materials processed at $77 \mathrm{~K}$, regardless of whether crystallization treatment was applied. Coercivity increased rapidly after the initial deformation steps, up to $\sim 45 \mathrm{~A} / \mathrm{m}$, after which continued processing led to a near-monotonic decrease to $\sim 5 \mathrm{~A} / \mathrm{m}$ to $15 \mathrm{~A} /$ $\mathrm{m}$.

Alloys 2A and 2B exhibited mostly similar fullfield induction values, which were relatively consistent after a single HPT revolution. Meanwhile, alloy 3 exhibited a notable decrease in induction after initial HPT deformation. Finally, the Finemet alloy exhibited peak full-field induction after two revolutions at $77 \mathrm{~K}$, and after three at $293 \mathrm{~K}$. The authors proposed that the shear stress imposed by HPT caused intraphase decomposition into nanoscale clusters with varying compositions, producing corresponding changes in magnetic properties. Magnetic property ranges were summarized to show permeability versus full-field induction, which suggests opportunities to tailor induction-permeability tradeoffs via HPT.

Following their work on amorphous alloys, Glezer et al. examined HPT processing of an equiatomic FeNi binary alloy. ${ }^{72}$ HPT was conducted at ambient temperature to develop a $55 \mathrm{~nm}$ to $60 \mathrm{~nm}$ grain size with a notable $\{111\}$-type crystallographic texture. Varying extents of local chemical ordering were measured, with increased HPT revolutions causing a transition from an $\mathrm{L}_{0}$ superlattice structure to short-range ordering. Magnetic properties analysis revealed a rotation-dependent trend in coercivity (increasing from $119 \mathrm{~A} / \mathrm{m}$ to to $\sim 557 \mathrm{~A} / \mathrm{m}$ ) and fullfield induction (peaking at $\sim 120 \mathrm{G} \mathrm{cm}^{3} / \mathrm{g}$, followed by a decay to $\sim 112 \mathrm{G} \mathrm{cm} / \mathrm{g}$ ). The resultant structure-sensitive magnetic properties evolution was discussed in terms of the ratio of deformation and dynamically annealed regions, wherein the emergence of annealed regions led to magnetically softer material. Variation in full-field induction values was proposed to result from local chemical ordering changes.

Glezer et al. then published a pair of studies on HPT processing of $\mathrm{Fe}-24$ at.\%Al alloy. ${ }^{73,74}$ Deformation was found to reduce chemical ordering compared with the annealed condition. Specifically, for the $\mathrm{DO}_{3}$ structure, all HPT conditions reduced this parameter to zero while the B2 structure approached zero up to 0.5 revolutions and increased with continued deformation. The authors proposed that the increase in B2 was the result of partial recovery of the atomic structure via low-temperature dynamic recrystallization, wherein grains 

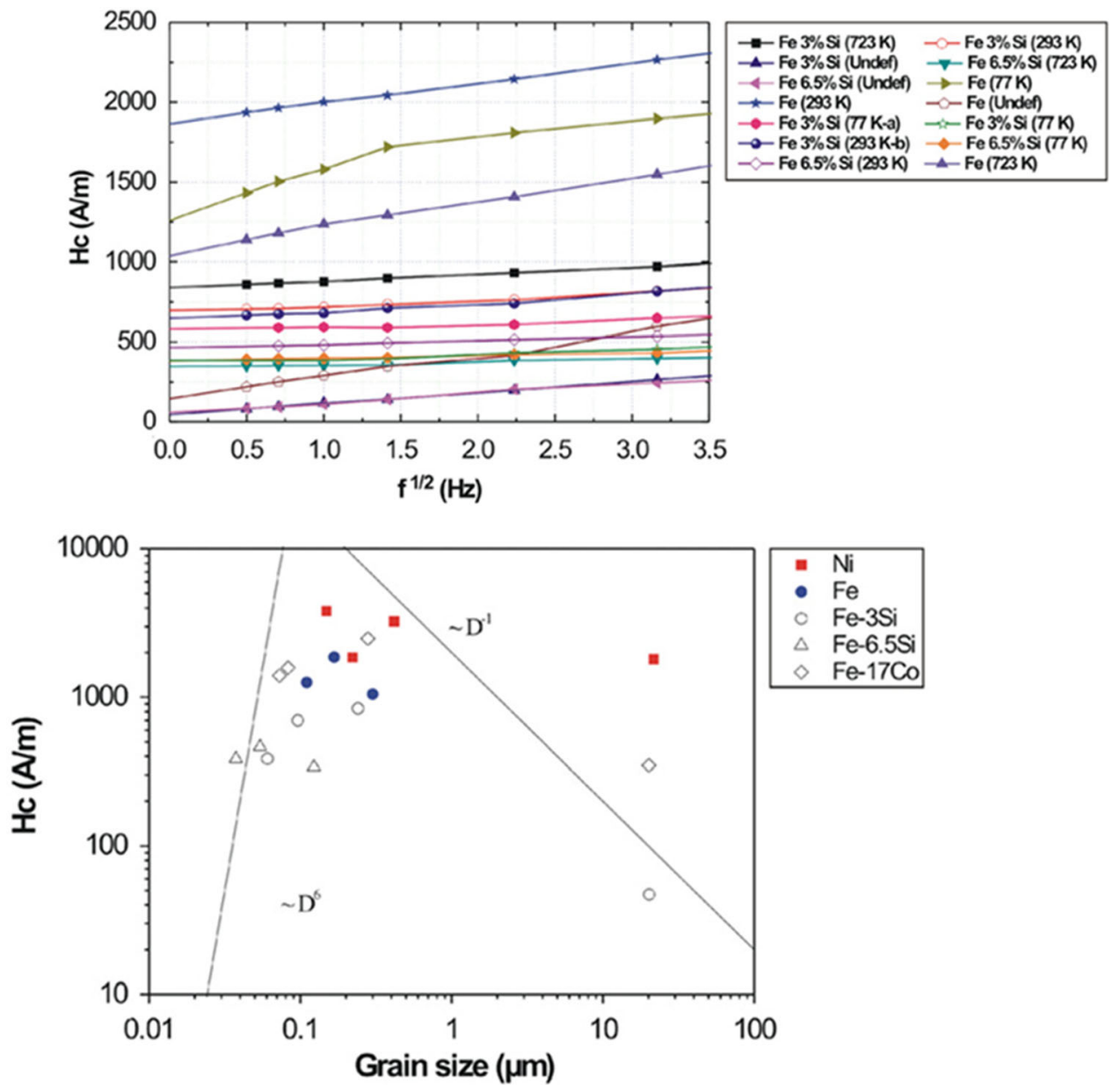

Fig. 8. Coercivity as a function of the square root of frequency (top) and grain size (bottom) for several soft-magnetic alloys processed via highpressure torsion. Reprinted with permission from Elsevier: Ref. 69-S. Scheriau, M. Kriegisch, S. Kleber, N. Mehboob, R. Grssinger, and R. Pippan, Magnetic characteristics of HPT deformed soft-magnetic materials, J. Magn. Magn. Mater. 322,2984 (2010).

contained a mixture of disordered BCC and ordered B2 structures. For magnetic properties, full-field induction was measured and peaked at 0.5 revolutions before achieving a slightly reduced steadystate value.

Recently, Glezer et al. examined HPT processing of $(\mathrm{Fe}-\mathrm{Co})_{100-x} \mathrm{~V}_{x}$ alloys $(X=0,1.5,3,4.5$, and 6$){ }^{75,76}$ Deformation was imposed at ambient and cryogenic $(77 \mathrm{~K})$ temperatures to develop microstructures with deformed and dynamically recrystallized regions (effective grain size of $50 \mathrm{~nm}$ to $250 \mathrm{~nm}$ ). The extent of the equilibrium ordered B2 structure decreased with increased revolutions. Microstructural refinement promoted high hardness, with post-HPT values $200 \%$ higher than for the initial workpiece in some cases. Due to strain hardening effects, coercivity values peaked during the initial stages of deformation before continued processing achieved a near steady-state value.

Abrosimova et al. and Aronin et al. ${ }^{77,78}$ evaluated HPT on Finemet-based amorphous magnetic alloys using ribbons as feedstock material. Following deformation, nanocrystals were formed within the initially amorphous matrix with a $\mathrm{Fe}_{3} \mathrm{Si}$ phase stoichiometry, also noted by Aronin et al., albeit with a smaller fraction. ${ }^{78}$ Full-field induction increased with increased HPT revolutions for both studies along with coercivity.

Hosokawa et al. explored HPT processing of pure $\mathrm{Fe}$ and $\mathrm{Fe}-\mathrm{Co}$ and $\mathrm{Fe}-\mathrm{Ni}_{3}$ alloys. ${ }^{79}$ HPT conducted at ambient temperatures resulted in drastically increased material hardness compared with the initial ingot because of grain refinement. Notably, the FCC-based $\mathrm{FeNi}_{3}$ alloy exhausted the extent of cold working after initial deformation steps, while the BCC-based materials continued to harden at much larger deformation strains. The initial, atomically ordered structures of the two alloys were lost with continued deformation. This group also published detailed crystallographic texture evolution. For pure $\mathrm{Fe}$ and $\mathrm{Fe}-\mathrm{Co}$, a slight texture was observed, characterized by $\langle 110\rangle$ parallel to the disc normal axis, while $\mathrm{Fe}^{-\mathrm{Ni}_{3}}$ formed a $<110>$ texture parallel to the hoop direction (i.e., shear direction). Full-field induction values were generally unchanged with continued deformation, with higher values for $\mathrm{Fe}$ and $\mathrm{Fe}-\mathrm{Co}$ compared with 
$\mathrm{Fe}-\mathrm{Ni}_{3}$. Coercivity was generally at the higher end, in agreement with Herzer model predictions. ${ }^{70}$

As a final example, Stückler et al. showcased HPT processing of soft-magnetic alloys in which elemental powders of $\mathrm{Fe}, \mathrm{Co}$, and $\mathrm{Cu}$ were consolidated with different volume fractions at ambient temperature and $500^{\circ} \mathrm{C}$, representing a significant portion of the ternary phase space (Fig. 9) ${ }^{80}$ To ensure powder consolidation and microstructural uniformity in billets, 50-150 anvil rotations were necessary. Microstructures were refined to a grain size of $\sim 66 \mathrm{~nm}$, resulting in a mixture of face-centered cubic (FCC) and BCC structures depending on alloy composition. Hardness values varied from $220 \mathrm{HV}$ to $780 \mathrm{HV}$, being highest for alloys with the smallest $\mathrm{Cu}$ content. Magnetic properties also revealed notable variation depending on alloy composition, where coercivity was highest for Fe-rich compositions, with values up to $3183 \mathrm{~A} / \mathrm{m}$.

While HPT has become a viable emerging manufacturing method for producing a wide array of bulk soft-magnetic alloys from various initial form factors, there are opportunities to continue developing a fundamental understanding of the structure-property relationships that result from HPT processing. Perhaps most notably, studies generally lack detailed characterization of crystallographic texture evolution. Given the importance of texture in controlling magnetic properties and anisotropy, future studies would benefit from incorporating these measurements. There are few reports on mechanical properties and associated deformation mechanisms for HPT-processed soft-magnetic alloys, which could be useful for high-performance applications. The use of powder as an initial feedstock is particularly noteworthy and should be explored further, given the potential for developing gradient alloy billets/discs. Finally, due to the mechanics of the process, spatial variation in microstructure will remain a notable feature and potential challenge for soft-magnetic alloys. It is thus recommended that future studies provide a more detailed analysis of the corresponding HPTinduced anisotropy in magnetic alloys.

\section{Accumulative Roll Bonding}

First reported by Saito et al., accumulative roll bonding (ARB) involves stacking together sheets of either similar or dissimilar composition and subjecting them to rolling reductions that simultaneously impose large deformation strains and metallurgically bond the stacked sheets together, creating a multilayered nanostructured

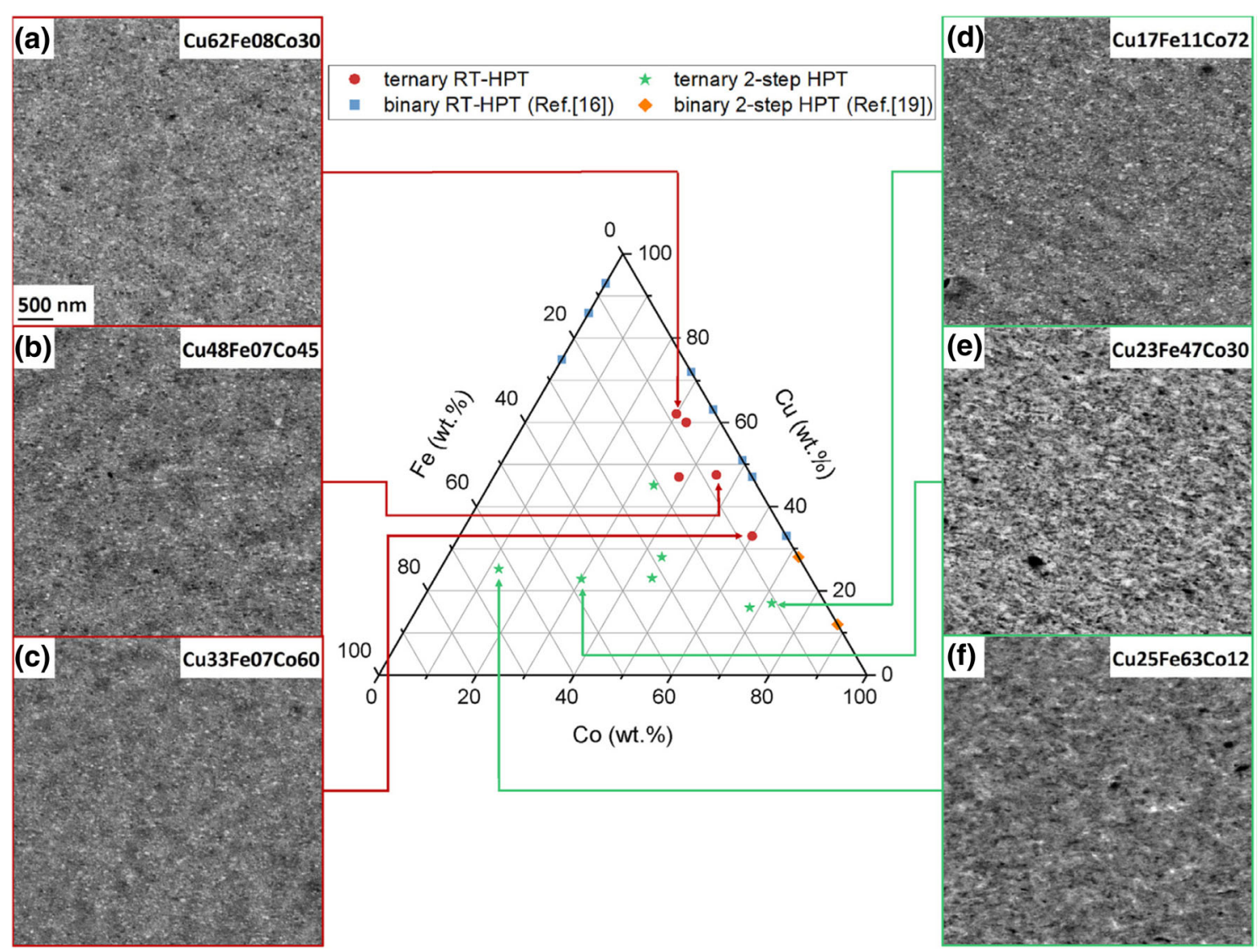

Fig. 9. Location of evaluated samples projected on ternary Fe-Co-Cu phase diagram with associated microstructures. Reprinted from Ref. 80, published by Elsevier B. V. under CC license (https://creativecommons.org/licenses/by/4.0/legalcode). 
laminate. ${ }^{81,82}$ The laminated structure is then sectioned in the length/rolling direction, restacked, and subjected to additional rolling deformation (Fig. 10). This process is repeated, enabling extremely large plastic strains in sheet far beyond conventional rolling. The effective strain imposed during deformation is proportional to the total number of deformation cycles. Processing can be performed at ambient or elevated temperatures, where higher temperatures aid metallurgical bonding but also alleviate accumulated plastic strain and the benefits of microstructural refinement.

The final mention of SPD processing is focused on $\mathrm{ARB}$, which has been explored in recent years to develop nanostructured laminates containing softmagnetic metals/alloys. Eslami et al. utilized ARB to produce $\mathrm{Cu}-\mathrm{Ni}$ laminates by preheating and rolling stacked sandwich samples. ${ }^{83}$ The strength and ductility of the multimaterial laminates increased with the number of ARB cycles, achieving a yield strength of $385 \mathrm{MPa}$ and ductility of $20 \%$. Hardness, which was measured for pure $\mathrm{Cu}$ and $\mathrm{Ni}$ layers, similarly increased with cycle count, up to $10.5 \mathrm{HV}$ and $13.2 \mathrm{HV}$, respectively. Also, with increased cycle number, the coercivity increased, which was proposed to be related to increased cold working and grain refinement from deformation, while full-field induction decreased. The authors also showed enhanced strength in the bulk laminate from necking and fragmentation of $\mathrm{Ni}$ sheets, creating a Ni-reinforced $\mathrm{Cu}$ matrix composite. This provided additional strength beyond deformationinduced work hardening and grain size refinement mechanisms. The composite effect also impacted

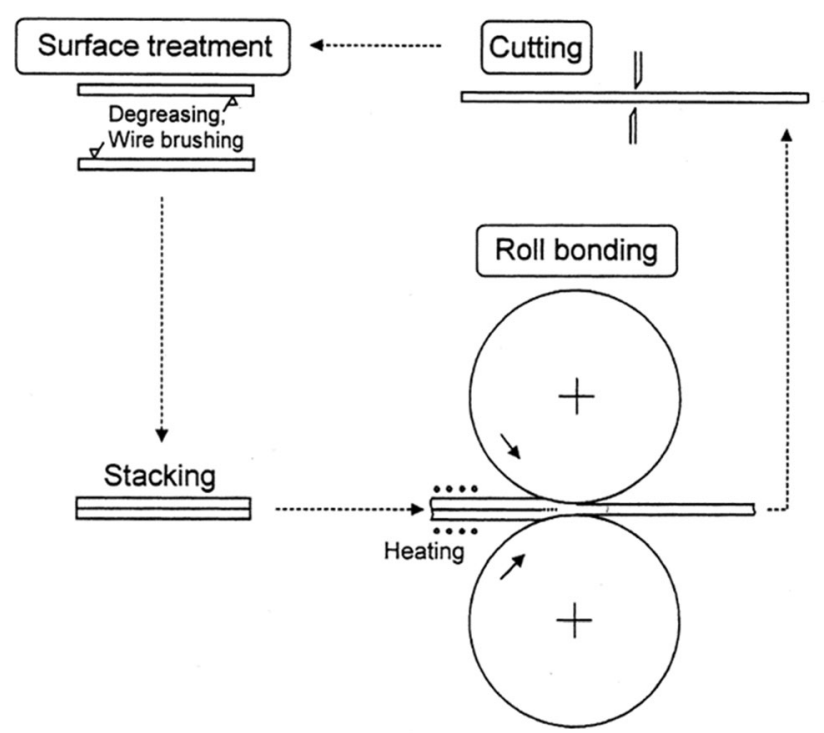

Fig. 10. Schematic of accumulative roll bonding process. Reprinted with permission from Elsevier: Ref. 81-Y. Saito, H. Utsunomiya, N. Tsuji, and T. Sakai, Novel ultra-high straining process for bulk materials-development of the accumluative roll-bonding (ARB) process, Acta Mater. 47, 579 (1999). ductility, wherein the softer $\mathrm{Cu}$ layer supported increased plastic straining.

Daneshvar et al. evaluated ARB processing of $\mathrm{Al}-$ $\mathrm{Ni}$ multilayer structures embedded with $\mathrm{Fe}_{3} \mathrm{O}_{4}$ particles as an additional magnetic and reinforcement phase. ${ }^{84}$ Production of the layered sheets involved sandwiching $\mathrm{Ni}$ between $\mathrm{Al}$ sheets and conducting primary rolling reductions of $50 \%$. Sheets were then sectioned, restacked, and again rolled to a $50 \%$ reduction. This process was repeated eight times. $\mathrm{Fe}_{3} \mathrm{O}_{4}$ (ferrimagnetic) particles were added (2 vol.\%) between the metal sheets in some samples. Deformation fragmented the Ni sheet and $\mathrm{Fe}_{3} \mathrm{O}_{4}$ particles. Initially, the particles exhibited poor bonding at the sheet-particle interfaces, but this improved with continued deformation. The Al$\mathrm{Ni}$ structures exhibited only a modest strengthening effect, while the $\mathrm{Fe}_{3} \mathrm{O}_{4}$ reinforced $\mathrm{Al}-\mathrm{Ni}$ strength decreased slightly (initially) before increasing again. The strength increase for the Al-Ni samples was attributed to work hardening and grain size refinement, while the initial strength decrease for the oxide-reinforced sample was proposed to result from poor particle bonding with the alloy matrix. Samples also exhibited notable uniform tensile elongation (10\%). Full-field induction values were lower for the oxide-reinforced samples due to their ferrimagnetic contribution to the overall laminate properties. Frequency-dependent properties were measured, and an optimum material design was identified for limiting eddy current losses by (1) reducing the $\mathrm{Ni}$ layer thickness and (2) the addition of the $\mathrm{Fe}_{3} \mathrm{O}_{4}$ particles. Example microstructures and properties of ARB-processed material are shown in Fig. 11.

Zhang et al. evaluated ARB-based processing for maraging steel (MAS) and conventional 316L. ${ }^{85}$ An initial stack, alternating between MAS and 316L, was hot pressed and then hot/cold rolled to obtain ultrathin laminated composites. The $316 \mathrm{~L}$ fragmented during deformation due to rapid work hardening. Strength and ductility decreased with increased rolling reductions, likely due to poor interface quality. Heat treatments were imposed to modify the MAS structure, one following a solutionizing and aging $\left(500^{\circ} \mathrm{C} / 4 \mathrm{~h}\right)$ treatment, and two additional aging-only treatments $\left(500^{\circ} \mathrm{C} / 2\right.$ or $\left.4 \mathrm{~h}\right)$. The former led to substantial strength reduction due to the removal of work hardening effects, while the latter promoted precipitation hardening/ strengthening. Full-field magnetic induction values varied from $122 \mathrm{~A} \mathrm{~m}^{2} / \mathrm{kg}$ to $158 \mathrm{~A} \mathrm{~m}^{2} / \mathrm{kg}$ for asdeformed material. Notably, full-field induction was enhanced beyond rule-of-mixture expectations $\left(98 \mathrm{~A} \mathrm{~m}^{2} / \mathrm{kg}\right.$ ) due to strain-induced (magnetic) martensite in the $316 \mathrm{~L}$ layers. Heat treatment reduced magnetic induction values due to (1) removal of deformation-induced martensite, (2) precipitation of nonmagnetic phases, and (3) development of reverted austenite in the MAS. 

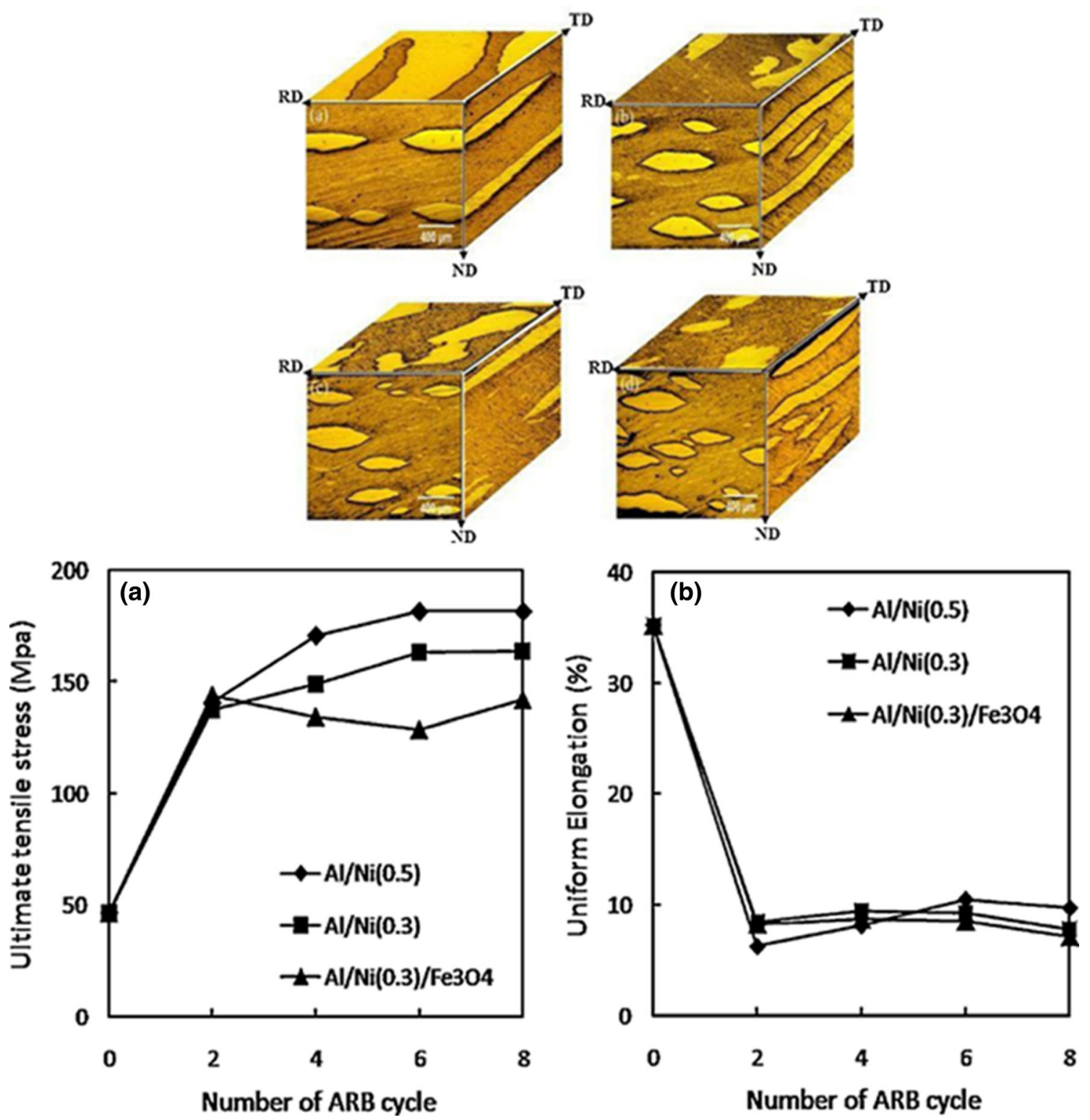

Fig. 11. Example microstructures of accumulative roll bonding Al/Ni composite and representative tensile properties. Reprinted with permission from Elsevier: Ref. 84-F. Daneshvar, M. Reihanian, and K. Gheisari, Al-based magnetic composites produced by accumulative roll bonding (ARB), Mater. Sci. Eng. B Solid-State Mater. Adv. Technol. 206, 45 (2016).

Finally, Zhu evaluated ARB processing of highpurity cobalt to a total $96.9 \%$ cumulative reduction. ${ }^{86}$ Microstructural analysis revealed an initial dual-phase material with hexagonal close-packed (HCP) $\alpha$-Co and $\beta$-Co (FCC) phases. With increasing deformation for the first three passes, the extent of the $\beta$-Co increased before saturating. Grain structures were refined to $\sim 1 \mu \mathrm{m}$, and the volume fraction of high-angle grain boundaries and twin boundaries increased with deformation. Crystallographic texture evolution was shown to develop a fiber-type texture for both HCP and FCC phases, while coercivity decreased with ARB pass number due to coupled grain size effects and an increase in the $\beta$-Co phase fraction.
One primary advantage of ARB processing seems to be the fabrication of multimaterial nanostructured layers that enable composite-type structures with unusual combinations of mechanical and magnetic properties. However, work related to the development of magnetic laminates remains relatively limited. It is advisable to explore the composite advantages of ARB processing with a broader suite of magnetic alloys, perhaps pairing lowstrength and/or low-ductility magnetic alloys with higher-strength and higher-ductility sheets, to create opportunities to overcome conventional softmagnetic alloy mechanical property limitations. Furthermore, there exists an exciting, but challenging, opportunity to incorporate less conductive or 
even nonconductive materials between soft-magnetic alloy layers to further restrict eddy current losses in frequency-based applications for higherefficiency devices.

\section{Advances in Melt Spinning}

Melt spinning and the production of amorphous and nanocrystalline alloy ribbons has been addressed thoroughly in other review articles. ${ }^{17,22,87-90}$ Thus, only a brief overview and recent developments are discussed here. First demonstrated by Duwez and Liz in 1967, ${ }^{91}$ melt spinning involves casting ribbons onto a rotating metallic wheel, with surface speeds of $10 \mathrm{~m} / \mathrm{s}$ to $40 \mathrm{~m} / \mathrm{s}$, to achieve cooling rates up to $1,000,000^{\circ} \mathrm{C} / \mathrm{s}$ that lock in amorphous structures. Melt spinning produces ribbons of material ranging in thickness from $5 \mu \mathrm{m}$ to $50 \mu \mathrm{m}$ and up to $25.4 \mathrm{~cm}$ in width. In general, the amorphous alloy composition is $\mathrm{T}_{70-80} \mathrm{M}_{30-20}$, where $\mathrm{T}$ is a magnetic transition metal ( $\mathrm{Fe}, \mathrm{Co}$, or $\mathrm{Ni}$ ) and $\mathrm{M}$ is some combination of metalloids (such as $\mathrm{B}, \mathrm{Si}$, $\mathrm{P}$, and C). ${ }^{22}$ Additional transition metals such as $\mathrm{Cu}, \mathrm{Zr}$, and $\mathrm{Nb}$ may be added in small amounts to control the nucleation and growth of the nanocrystalline soft-magnetic phase. ${ }^{92,93}$

Recent focus on melt-spun alloys includes tuning their stoichiometry, particularly through the inclusion of $\mathrm{Co}$ and $\mathrm{Ni}$, to enhance performance metrics for electromagnetic applications. In one report, amorphous alloys achieved saturation magnetic induction values of $1.63 \mathrm{~T}$ and nanocrystalline foils reached levels of $1.9 \mathrm{~T} .{ }^{94}$ This was accomplished through either increasing the iron content or including cobalt. The inclusion of cobalt can increase the Curie temperature, and therefore the maximum operating temperature, of the soft-magnetic alloy. ${ }^{95}$ In another report, nickel additions decreased the coercivity in amorphous alloys, while also increasing the foil ductility. ${ }^{96}$ Even further reductions in alloy coercivity were observed by the substitution of 10 at. $\%$ Fe with $\mathrm{Ni},{ }^{97}$ along with an observed decrease in the nanocrystallite size and a BCC to FCC transition in the crystallites. In addition to chemistry changes, the use of rapid annealing $(<10 \mathrm{~s})$ produced $\mathrm{Fe}-\mathrm{Si}$ nanocrystallites $30 \%$ smaller in comparison with conventional annealing processes. ${ }^{98}$ Finally, there have been initial successes in fabricating $6.5 \mathrm{wt} . \% \mathrm{Si}$ steel via melt spinning, offering an alternative to CVD. ${ }^{13,99}$

\section{Powder-Based Techniques}

Emerging powder-based techniques invariably require powder feedstock preparation, briefly discussed here. Often, mechanical alloying (MA) and/or milling steps are employed with high-quality initial alloy powders produced via water or gas atomization. Ali and Ahmad provided a thorough review of processing techniques for $\mathrm{Fe}-\mathrm{Ni}$ soft-magnetic materials, including powder preparation methods, which are applicable to all soft-magnetic alloys. ${ }^{6}$ They discussed the importance of ball milling for particle size and agglomeration reduction to improve the powder rheological properties. Furthermore, prior to sintering, MA powders can have a pronounced benefit through enhancements in powder surface energy. For instance, Ali and Ahmad compared Fe$\mathrm{Ni}$ powders sintered as received and after highenergy ball milling, with milled powders showing improvements in compact density and relative permeability. ${ }^{6}$ They cautioned of increased strain and coercivity in such powders, which can be reduced through postprocessing annealing. However, studies have demonstrated that tuning milling parameters can lessen the increase in coercivity. ${ }^{100}$

\section{Spark Plasma Sintering}

Spark plasma sintering (SPS), also called currentactivated pressure-assisted densification (CAPAD), is a material consolidation method using the simultaneous application of current and pressure to consolidate powder feedstock more rapidly (i.e., in a few minutes) than conventional sintering (hours/days). Several comprehensive SPS review articles provide substantial additional information on this technique, ${ }^{101-103}$ which lies beyond the scope of this review. Briefly, standard SPS instruments include a vacuum chamber, electrodes/plungers for the application of both current and pressure, and a power supply capable of delivering the high electric currents necessary for sintering. An example schematic of the process is shown in Fig. $12 .^{104}$

SPS has been used for the consolidation of both hard- (permanent) ${ }^{105}$ and soft-magnetic materials. However, the existing SPS literature remains relatively small, with substantial opportunities for exploration with soft-magnetic alloys. Due to its relatively low processing temperatures and short processing times, SPS can limit grain growth during densification and therefore fabricate nanocrystalline materials. ${ }^{101}$ This lends itself well to the production of soft-magnetic materials with low coercivities. ${ }^{89}$

Kim and coworkers ${ }^{106}$ demonstrated the fabrication of Fe-Co alloys by employing milling for both MA and grain refinement. Following the milling step, the MA powders were consolidated using SPS. A key conclusion in Kim's paper was that coercivity increased as a function of milling time and postconsolidation annealing was necessary to reduce the coercivity in consolidated materials.

SPS can also take advantage of phase transitions occurring within the processing temperature to form intimately mixed nanocomposites. Morales et al. demonstrated this by sintering nanopowders of maghemite $\left(\gamma-\mathrm{Fe}_{2} \mathrm{O}_{3}\right){ }^{107,108}$ Cubic $\gamma-\mathrm{Fe}_{2} \mathrm{O}_{3}$ (ferrimagnetic) transforms into hexagonal $\alpha-\mathrm{Fe}_{2} \mathrm{O}_{3}$ (antiferromagnetic) at $300^{\circ} \mathrm{C}$, and $\alpha-\mathrm{Fe}_{2} \mathrm{O}_{3}$ partially reduces to cubic $\mathrm{Fe}_{3} \mathrm{O}_{4}$ (ferrimagnetic) at $600^{\circ} \mathrm{C}$. $^{108}$ This resulted in magnetic properties for iron oxide nanocomposites that can be tuned through the 


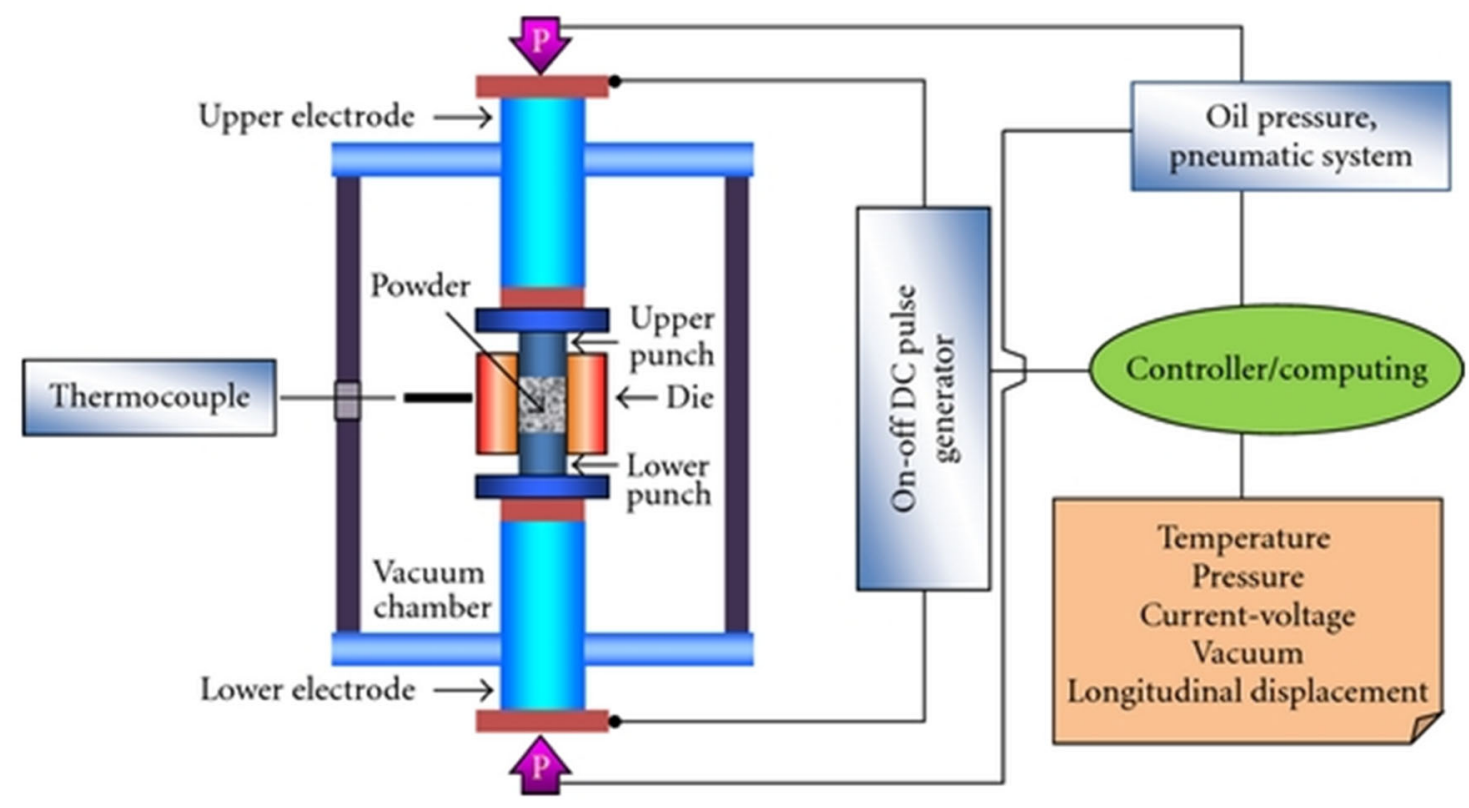

Fig. 12. Schematic of spark plasma sintering process. Reprinted from Ref. 104 by Hindawi under CC license (https://creativecommons.org/lice nses/by/3.0/legalcode).

sintering temperature and grain size dependent exchange coupling. Fei and coauthors saw related results when using SPS to fabricate a nanocomposite of magnetically hard cobalt ferrite $\left(\mathrm{CoFe}_{2} \mathrm{O}_{4}\right)$ and magnetically soft magnetite $\left(\mathrm{Fe}_{3} \mathrm{O}_{4}\right){ }^{109}$ They also observed exchange coupling that could be tuned based on the sintering temperature.

A soft-magnetic composite (SMC) consisting of an electrically conductive magnetic phase (iron) and a nonmagnetic insulating phase (borosilicate glass or Pyrex) was fabricated by Gheiratmand and coworkers. ${ }^{110}$ The inclusion of the electrically insulating borosilicate boosted the electrical resistivity and decreased the eddy current losses in the resulting composites. Using SPS, they were able to achieve a nearly full dense (99.9\% full density) sample containing 3 wt.\% borosilicate. However, the best-performing sample in terms of density, permeability, and electrical resistivity contained $2 \mathrm{wt} . \%$ borosilicate.

SPS can also be used as a tool for the creation of compositionally graded soft-magnetic materials, as demonstrated by Chaudhary and coworkers. ${ }^{111}$ Loading different compositions of the ternary alloy $\mathrm{Fe}-\mathrm{Co}-\mathrm{Ni}$ into a graphite die, they completed an array of characterization measurements to assess structure, magnetic/mechanical properties, and electrical resistivity as functions of composition. Their work established that SPS can accelerate the screening of magnetic alloys and develop graded materials that are useful in high-speed electrical machines.

Finally, SPS has been utilized for fabricating softmagnetic high-entropy alloys (HEAs). ${ }^{112} \mathrm{Fu}$ and colleagues reported on SPS formation of Fe-Co-Nibased alloys, but with manganese and copper added to form a HEA. ${ }^{112}$ The stoichiometry $\mathrm{Fe}_{30} \mathrm{Ni}_{30}$ $\mathrm{Co}_{29} \mathrm{Mn}_{5.5} \mathrm{Cu}_{5.5}$ was selected based on simulation results. Ti was then added to form the composite $\mathrm{TiC} / \mathrm{Fe}_{30} \mathrm{Ni}_{30} \mathrm{Co}_{29} \mathrm{Mn}_{5.5} \mathrm{Cu}_{5.5}$, further improving mechanical properties over more traditional $\mathrm{Fe}-\mathrm{Co}-$ Ni-based alloys. Fu and coworkers leveraged the localized overheating that sometimes occurs during SPS $^{113,114}$ to facilitate the heterogeneous recrystallization of $\mathrm{TiC}$ and form a high-entropy composite (HEC), yielding a soft-magnetic alloy with an unusual combination of strength and ductility compared with other HEAs. ${ }^{112}$

SPS remains an underutilized unconventional manufacturing route for bulk soft-magnetic alloy production. The opportunity to tailor composition, and thus spatially dependent mechanical and magnetic properties via grading or extensive alloying, is a particularly promising area that is recommended for future studies. This is especially true for advanced soft-magnetic materials discovery, highentropy alloys, and bulk soft-magnetic composites that are impractical to process with other routes. Furthermore, it is recommended that studies characterize mechanical properties in greater detail.

\section{Metal Injection Molding}

Metal injection molding (MIM) is a powder metallurgy (PM)-based manufacturing method that combines plastic injection molding principles with conventional powder metallurgy practices to achieve near-net-shape parts. ${ }^{115}$ The process uses 
fine metal powder that is mixed with an organic binder, e.g., thermoplastic, to form an initial feedstock mixture before use in molding operations. The mixture is granulated/pelletized and used with an injection molding machine and associated tooling/ die designs to create complex parts at high production speeds. Processing parameters, such as pressure and temperature, are varied to obtain suitable flow of the feedstock slurry. Once injected into the mold cavity, parts are removed from the tooling in a "green" state, then post-processed through sequential steps of thermal debinding (removal of the polymer) and sintering to achieve the final desired density, part size/tolerance, and microstructure (Fig. 13). ${ }^{116}$

MIM processing remains one of the most popular unconventional powder-based processing routes for producing bulk soft-magnetic alloys. With initial reports dating back to the $1980 \mathrm{~s}$, MIM has been utilized to develop bulk parts from several magnetic alloys. A summary of key information from these studies is provided in Supplementary Table S2.

An early report by Barrow summarized emerging trends in PM. ${ }^{117}$ At the time, MIM had evolved from basic laboratory research to a viable approach for manufacturing soft-magnetic alloy parts, with distinct advantages over conventional PM, most notably the (1) development of higher-density compacts and (2) ability to process high-silicon-content $\mathrm{Fe}-\mathrm{Si}$ alloys. Typical properties were summarized for $\mathrm{Fe}-$ 2 wt. $\%$ Ni, Fe-50 wt. $\%$ Ni, Fe-3 wt. $\% \mathrm{Si}$, and Fe6 wt.\%Si alloys. Shortly thereafter, a perspective piece by Merhar included additional nominal properties of select MIM soft-magnetic alloys, with an emphasis on mechanical performance. 115

A series of studies were conducted by Miura et al. on MIM processing of soft-magnetic alloys. ${ }^{118-120}$ Initial efforts were focused on $\mathrm{Fe}-\mathrm{Ni}$ and $\mathrm{Fe}-\mathrm{Si}$ alloys with $\mathrm{Ni}$ and $\mathrm{Si}$ contents varying from 0 mass\% to 9 mass\%, sintered at $1573 \mathrm{~K}(\mathrm{Fe}-\mathrm{Ni})$ or $1523 \mathrm{~K}(\mathrm{Fe}-\mathrm{Si})$ for $1 \mathrm{~h}$. Vacuum and hydrogen environments were explored, and final (relative) densities of $96 \%$ were obtained. Full-field induction values for the $\mathrm{Fe}-\mathrm{Ni}$ alloys showed a notable increase with increased $\mathrm{Ni}$ content for the vacuum environment, while $\mathrm{Fe}-\mathrm{Si}$ alloys with increased $\mathrm{Si}$ content showed a lower magnetic induction regardless of atmosphere. Coercivity and strength values generally increased with increasing solute composition for both alloy systems. Fe-Ni alloys increased in ductility with $\mathrm{Ni}$ content until $\sim 3 \% \mathrm{Ni}$, while $\mathrm{Fe}-\mathrm{Si}$ showed a sharp decrease with increased Si-content down to $0 \%$ strain-to-failure.

Miura et al. then evaluated MIM processing of $\mathrm{Fe}-$ 9.5Si-5.5Al (so-called Sendust alloy) soft-magnetic alloy using both gas- and water-atomized powder. ${ }^{119}$ Samples were sintered at $1473 \mathrm{~K}$ to $1543 \mathrm{~K}$ for $1 \mathrm{~h}$ under hydrogen or vacuum, followed by annealing at $1173 \mathrm{~K}$ for $6 \mathrm{~h}$. A second set of samples were also prepared by a "continuous" process wherein debinding and sintering were performed without an intermediary cool down. Alloy densities increased with sintering temperature (a common theme in MIM literature), achieving a maximum relative density of $99 \%$, while coercivity decreased to a minimum of $\sim$ $5.6 \mathrm{~A} / \mathrm{m}$. Full-field induction was largely constant, if not slightly increasing, with increased sintering temperature. Compared with conventional material, MIM-processed alloys were magnetically harder.

Miura et al. published a comprehensive MIM study that included their findings on Sendust alloy in addition to $\mathrm{Fe}-6.5 \mathrm{wt} . \% \mathrm{Si}$ and $\mathrm{Fe}-50 \mathrm{wt} . \% \mathrm{Ni}$ alloys. ${ }^{120}$ The Fe-Si alloy was sintered at $1423 \mathrm{~K}$ to $1623 \mathrm{~K}$ for $1 \mathrm{~h}$ to $3 \mathrm{~h}$ without a secondary annealing treatment, while the $\mathrm{Fe}-\mathrm{Ni}$ alloy was annealed at $1373 \mathrm{~K}$ for $2 \mathrm{~h}$. In the case of $\mathrm{Fe}-\mathrm{Si}$, samples were fabricated using water $\left(W_{\mathrm{H}}\right)$ or gas atomized powder, with the latter having two different oxygen purities $\left(G_{\mathrm{M}}=\right.$ higher impurity content, $G_{\mathrm{L}}=$ lower impurity content). Given the effect of impurities on magnetic properties, they are often quantified in MIM studies. For Fe-Ni, compacts were fabricated with both elemental and prealloyed

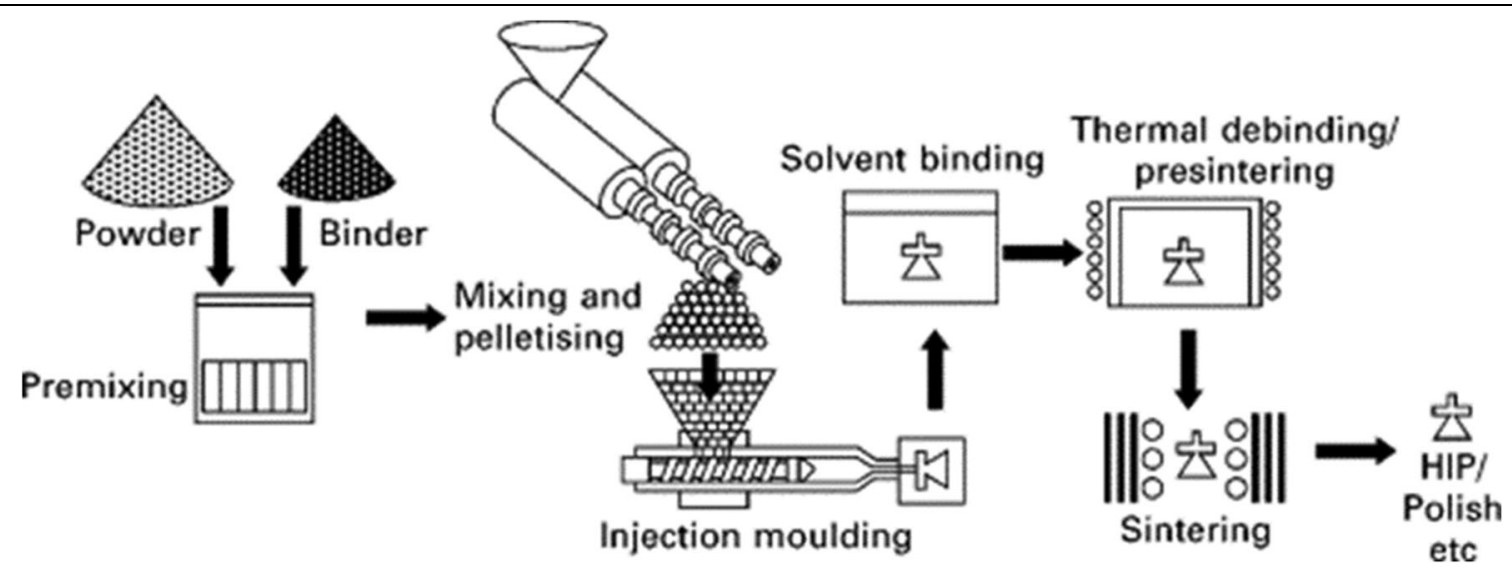

Fig. 13. Flow diagram for metal injection molding. Reprinted with permission from Elsevier: Ref. 116-I. Todd and A. T. Sidambe, Chapter 6 Developments in metal injection moulding (MIM), in Adv. Powder Metall. (Elsevier, 2013). 
powder. As expected, density again increased with sintering temperature, approaching 99\% of full density. Full-field induction values were $1.5 \mathrm{~T}$ and $1.55 \mathrm{~T}$ while minimum coercivity was $32 \mathrm{~A} / \mathrm{m}$ and $20 \mathrm{~A} / \mathrm{m}$ for $\mathrm{Fe}-\mathrm{Si}$ and $\mathrm{Fe}-\mathrm{Ni}$ alloys, respectively. After sintering, MIM compacts produced using $\mathrm{G}_{\mathrm{L}}$ powder exhibited significant grain growth and, consequentially, the softest magnetic properties (see Fig. 14 for Fe-6.5 wt.\%Si properties). Frequency-dependent magnetic properties did not exhibit a strong correlation with relative density.

A set of MIM studies were also conducted by Ma et al., focused on Fe-Ni and Ni-P alloys. ${ }^{121,122}$ In one study, ${ }^{122}$ MIM samples were sintered with a range of temperatures and times, bounded by $1110^{\circ} \mathrm{C}$ for $2 \mathrm{~h}$ up to $1360^{\circ} \mathrm{C}$ for $10 \mathrm{~h}$, where higher sintering

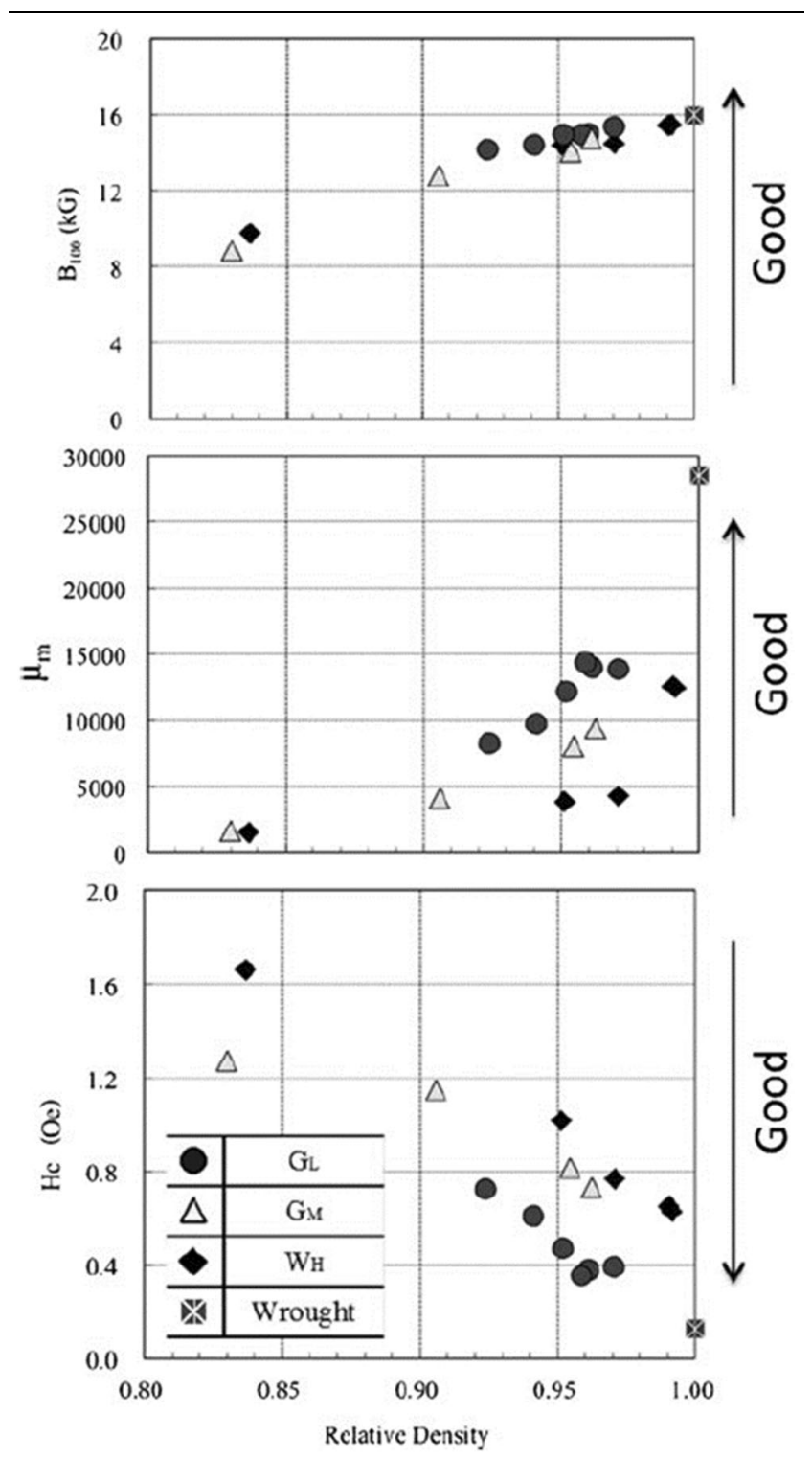

Fig. 14. Magnetic properties for metal-injection-molded Fe-6.5 wt.\%Si. Reprinted with permission from Taylor \& Francis: Ref. $120-\mathrm{H}$. Miura and $\mathrm{H}$. Kang, Application of metal injection moulding to soft magnetic materials, Powder Metall. 56, 38 (2013). temperatures resulted in higher relative density and softer magnetic performance. Sintering atmosphere was also explored, including $\mathrm{N}_{2}, \mathrm{Ar}, \mathrm{H}_{2}$, and vacuum. Their second study incorporated an additional HIP step at $1050^{\circ} \mathrm{C}$ for $3 \mathrm{~h}$ and final heat treatment at $1200^{\circ} \mathrm{C}$ for $2 \mathrm{~h}$ to $10 \mathrm{~h}$ under an $\mathrm{H}_{2}$ atmosphere. ${ }^{121}$ Higher density values improved the full-field induction properties, while sintering for longer times improved the softer structure-sensitive properties due to grain growth and reduction of residual stress/dislocation density. After HIP, fullfield induction values increased, albeit with an increase in coercivity. Thus, "optimized" samples were achieved using both HIP and post-HIP heat treatment.

$\mathrm{Ma}$ et al. then evaluated the $79 \mathrm{Ni}-4 \mathrm{Mo}-\mathrm{Fe}$ softmagnetic alloy, similar to the permalloy-type alloys. ${ }^{123}$ As with their prior studies, elemental powders were utilized for MIM processing. Samples were sintered at $1240^{\circ} \mathrm{C}$ to $1360^{\circ} \mathrm{C}$ for various times in a hydrogen atmosphere. The highest density was achieved at $1320^{\circ} \mathrm{C}$ after $10 \mathrm{~h}$. Soft-magnetic properties similarly improved with increased density.

Finally, these authors evaluated $\mathrm{Fe}_{3} \mathrm{P}$ additions to MIM-processed $\mathrm{Fe}$, with $\mathrm{Fe}-x \mathrm{P}(x=0$ wt.\% to 1.2 wt.\%). ${ }^{124}$ Elemental $\mathrm{Fe}$ and alloyed $\mathrm{Fe}_{3} \mathrm{P}$ powder were utilized as feedstock to produce samples that were then sintered at $1100^{\circ} \mathrm{C}$ to $1450^{\circ} \mathrm{C}$ for various times in hydrogen atmosphere. Relative density varied with sintering temperature and alloy composition, with a sharp increase in density at lower temperatures for alloys with $\mathrm{P}$ additions due to a peritectic reaction that created partial liquid-phase sintering, a noteworthy effect that seems to be rarely utilized by the MIM soft-magnetics community. Optimum magnetic properties were achieved for alloys with 0.8 wt. $\% \mathrm{P}$ due to full dissolution of $\mathrm{P}$ into the alloy matrix, thus avoiding magnetic domain pinning.

Páez-Pavón et al. published a pair of MIM studies on Fe-Si alloys with a focus on thermal debinding effects on $\mathrm{Fe}-3.8$ wt.\%Si performance, while their second study targeted sintering effects on this alloy and Fe-6.5 wt.\% Si alloy. ${ }^{125,126}$ The two debinding cycles involved heating from ambient to $250^{\circ} \mathrm{C}$ at $5^{\circ} \mathrm{C} / \mathrm{min}$ and $1^{\circ} \mathrm{C} / \mathrm{min}$, and $250^{\circ} \mathrm{C}$ to $500^{\circ} \mathrm{C}$ at $2^{\circ} \mathrm{C} /$ min and $1^{\circ} \mathrm{C} / \mathrm{min}$ (cycle 1 and cycle 2 , respectively). ${ }^{125}$ The authors found that the second debinding cycle led to higher density, lower oxygen content, and thus improved mechanical and magnetic properties. For the second study, the authors evaluated different atmospheres $\left(\mathrm{H}_{2}, \mathrm{~N}_{2}-5 \% \mathrm{H}_{2}, \mathrm{Ar}\right.$, and vacuum), as well as temperatures ranging from $1300^{\circ} \mathrm{C}$ to $1400^{\circ} \mathrm{C}$ for $2 \mathrm{~h}$ to $4 \mathrm{~h} .{ }^{126}$ Some key results include: (1) hydrogen produced the highest relative density at a given temperature, and the highest fullfield induction for $\mathrm{Fe}-3.8$ wt.\% $\mathrm{Si}$ (Fe-6.5 wt.\%Si was similar for both vacuum and hydrogen atmospheres), (2) density generally saturated at $1350^{\circ} \mathrm{C}$ for both alloys, and (3) sintering at $1400^{\circ} \mathrm{C}$ in hydrogen produced the highest full-field induction. 
Among the most recent studies is that by Zhang et al., who evaluated MIM processing of Fe-35 wt.\% Co alloy sintered at temperatures of $1275^{\circ} \mathrm{C}$ to $1375^{\circ} \mathrm{C}$ in $\mathrm{Ar}+2 \% \mathrm{H}_{2}$ atmosphere. ${ }^{127}$ Following processing, the Fe-Co samples exhibited the equilibrium ordered B2 structure, with an equiaxed grain morphology that had no preferred crystallographic texture. Density increased with increasing sintering temperature, along with improved softmagnetic properties characterized by higher fullfield induction and reduced coercivity. The authors provided an analysis of grain-size-dependent properties, finding a linear regression fit for coercivity, in agreement with Herzer, ${ }^{70}$ expressed as $H_{\mathrm{c}}=21.88$ $+5.34 / d$ where $d$ is grain size.

MIM enables bulk processing of a variety of softmagnetic alloys, and a strong body of literature has been developed in this area. Continued exploration of MIM is recommended, especially to integrate nonmagnetic and magnetic alloys within a single specimen to achieve potentially improved mechanical-magnetic property relationships through a composite-type effect. Additionally, more studies could focus on detailed mechanical properties characterization and more explicit determination of process-induced magnetic anisotropy.

\section{Spray-Based Methods}

Other predominately powder-based methods for producing magnetic materials are thermal spray and cold spray processing. The former represents a broad class of processes that enable thick coatings through high-energy and high-velocity $(50 \mathrm{~m} / \mathrm{s}$ to $1000 \mathrm{~m} / \mathrm{s}$ ) deposition of feedstock (powder or wire/ rod) in a molten or semimolten state. ${ }^{128}$ Liquified or thermally softened feedstock materials are propelled toward a substrate to form thin "splats" upon impact. Coatings are then rapidly built up in thickness on the substrate through the accumulation of overlapping splats, creating a layered and often porous microstructure. The high energy utilized during processing, coupled with the splat size, enables rapid solidification, with individual splat cooling rates typically higher than $1,000,000^{\circ} \mathrm{C} / \mathrm{s} .{ }^{128}$ Thermal spray methods are based on flame, electric, and plasma arc deposition technologies.

High-pressure cold spray, a similar yet distinct coating method to thermal spray, is a solid-state coating deposition process in which metal feedstock powder is sprayed at high velocity $(500 \mathrm{~m} / \mathrm{s}$ to $1000 \mathrm{~m} /$ s) and low temperature (as low as room temperature) to create thick coatings. ${ }^{129-133}$ In contrast to thermal spray, an advantage of cold spray is that it produces a "clean" coating/material with little or no oxide, which is desirable for soft-magnetic performance, with low thermal input to the underlying structures, enabling integration with other materials.

Several researchers have investigated spray processing of magnetic alloys and evaluated the resultant magnetic properties. ${ }^{10,134-139}$ Kasama et al. ${ }^{10,134}$ conducted research on thermal spray formed and subsequently rolled Fe- 6.5 wt. $\% \mathrm{Si}(+1.0$ wt.\% $\mathrm{Al}$ ) and $\mathrm{Fe}-3$ wt.\%Si-3.5 wt.\% $\mathrm{Al}$ alloys. The high cooling rates altered the ordering of the alloy to avoid embrittlement and (along with the addition of $\mathrm{Al}$ ) allowed for subsequent hot rolling of the sprayed material. The coercivity varied from about $80 \mathrm{~A} / \mathrm{m}$ to $111 \mathrm{~A} / \mathrm{m}$ for the as-sprayed or sprayed + rolled materials. Heat treatments $\left(700^{\circ} \mathrm{C}\right.$ and $\left.1250^{\circ} \mathrm{C}\right)$ decreased the coercivity relative to the as-sprayed condition due to the annealing process. A review by Sampath in 2010 summarized research on permanent-magnet materials ( $\mathrm{SmCo}$ and $\mathrm{Nd}-\mathrm{Fe}-\mathrm{B}$ ) and ferrite materials ( $\mathrm{MnMg}, \mathrm{Y}-\mathrm{Fe}, \mathrm{MnZn}$, and NiZn), as well as soft-magnetic FeSi-based alloys. ${ }^{135}$ Of particular interest, high-velocity oxyfuel (HVOF) technology has been used extensively to produce the soft-magnetic alloys FeSi and FeNb. ${ }^{136-139}$ HVOF develops coatings with relatively low porosity, high strength, and relatively low oxide content compared with other thermal spray processes. The high quench rates during spray deposition can suppress crystallization and maintain some amount of amorphous material. Parker et al. used HVOF to deposit amorphous $\mathrm{Fe}_{75} \mathrm{Si}_{15} \mathrm{~B}_{10}$ powder, with the resultant coatings exhibiting properties similar to those of powders produced by spark erosion. ${ }^{136}$ Cherigui et al. sprayed $\mathrm{FeSi}, \mathrm{FeNb}$, and $\mathrm{FeSiB}$ with $\mathrm{HVOF}$, and the deposits showed porosity of $3.5 \%$ to $8 \%{ }^{137-139}$ They found that the coercivity of HVOF Fe-6.5 wt. $\%$ Si was $398 \mathrm{~A} / \mathrm{m}$ to $637 \mathrm{~A} / \mathrm{m}$, compared with $318 \mathrm{~A} / \mathrm{m}$ for the powder itself, both of which are far above typical values for wrought FeSi alloys. The higher coercivity in the sprayed deposits relates to inhibited domain wall movement due to inhomogeneities, such as inclusions, dislocations, oxide, voids, and internal stress within the coatings. In a later study, deposits from mechanically alloyed powders of $\mathrm{FeSi}$ alloys, with or without additions of $\mathrm{B}, \mathrm{Nb}$, and $\mathrm{Cu}$, exhibited lower coercivities than the powders themselves, possibly due to the formation of mixed amorphous and nanostructured phases. ${ }^{139}$ The materials displayed stable coercivities with annealing temperatures up to $400^{\circ} \mathrm{C}$. Cherigui et al. also noted that the standoff distance was the dominant spray process parameter affecting both the coercivity and the full-field magnetization of $\mathrm{FeNb}$. These results were correlated to porosity and the phases formed in the sprayed deposit. They concluded that $\mathrm{FeSiBNbCu}$ was the optimal alloy for magnetic shielding applications.

In most cold spray studies, magnetic feedstock particles are co-deposited with ductile powders to create consolidated composite coatings of brittle particles in a ductile matrix. $\mathrm{Li}$ and $\mathrm{Li}$ used elemental $\mathrm{Fe}$ and $\mathrm{Si}$ powders mechanically alloyed via ball milling as their feedstock to deposit coldsprayed soft-magnetic Fe-Si alloy coatings with a nanocrystalline microstructure. ${ }^{140}$ The microhardness was $\sim 400 \mathrm{HV}$, attributed to a highly coldworked nanostructure after deposition, as well as 
the incorporation of oxide from the ball milling process. For similar reasons, the coercivity of the material was three to four orders of magnitude higher than typical Fe-Si alloys, suggesting that the deposit could be a candidate for magnetic recording devices. Using a similar ductile matrix concept, Van Steenkiste documented the physical, magnetostrictive, and magnetic properties of rare-earth iron alloys (Terfenol-D ( $\left.\left(\mathrm{Tb}_{0.3} \mathrm{Dy}_{0.7}\right) \mathrm{Fe}_{1.9}\right)$ and $\left.\mathrm{SmFe}_{2}\right)$ codeposited with several metals $(\mathrm{Al}, \mathrm{Cu}, \mathrm{Fe}$, and Mo). ${ }^{141}$ Aluminum appeared to be the most popular ductile matrix material for codeposition. Cherigui et al. used nanostructured ferromagnetic FeSiBNbCu (Finemet) powders mixed with varying percentages of $\mathrm{Al}$, yielding a consolidated, ultrafine-grained, cold-sprayed coating. ${ }^{142}$ It was found that $25 \% \mathrm{Al}$ was ideal to produce homogeneous coatings with suitable soft-ferromagnetic behavior, despite the $\mathrm{Al}$ being nonmagnetic. The coercivities of the coatings ranged from about $80 \mathrm{~A} / \mathrm{m}$ to $1751 \mathrm{~A} /$ $\mathrm{m}$. Similarly, King et al. and later, Lamarre and Bernier, deposited permanent-magnet/aluminum composites made from $\mathrm{Nd}-\mathrm{Fe}-\mathrm{B}$-based powders mixed with $\mathrm{Al}$ powder as a ductile binder. ${ }^{143,144} \mathrm{In}$ this case, due to large particle size, the hardmagnetic particles tended to fracture upon impact while the $\mathrm{Al}$ underwent severe plastic deformation and trapped the Nd-Fe-B particles within the coatings. The magnetic properties of the Nd-Fe-B were largely unaffected by the cold spray process. ${ }^{143}$ King and coworkers also used cold spray to produce iron (Fe), as well as Terfenol-D codeposited with aluminum. There was an increase in the coercivity of the Al/Terfenol-D mixture from $12.7 \mathrm{kA} / \mathrm{m}$ to $25.5 \mathrm{kA} / \mathrm{m}$ following cold spray, but there was no change in that of iron (or $\mathrm{Al} / \mathrm{Nd}_{2} \mathrm{Fe}_{14} \mathrm{~B}$ ). Lamarre and Bernier also deposited pure Fe powder via cold spray with $800^{\circ} \mathrm{C}$ gas temperature, to serve as filler material between $\mathrm{Nd}-\mathrm{Fe}-\mathrm{B}$ permanent rotor magnets. ${ }^{144}$ Thus, cold spray Fe was not the primary focus of their study. Ultimately, they produced unique spray-formed and machined components with alternating zones of $\mathrm{NdFeB}-\mathrm{Al}$ and soft-magnetic iron.

Spray processes remain a promising alternative approach for production of bulk soft-magnetic alloys as thick coatings or claddings. However, studies to date have been limited to a relatively small subset of alloys and exclude characterization of important mechanical and anisotropic magnetic properties. Thus, it is recommended that future studies explore a wider array of alloys, in particular by co-spraying magnetic and nonmagnetic materials, targeting opportunities to overcome conventional magneticmechanical property tradeoffs through compositetype effects.

\section{Additive Manufacturing}

Additive manufacturing (AM) is an increasingly popular approach for producing near-net-shape metal components through layerwise fabrication to enable material combinations/designs that are impractical to produce with conventional processes. ${ }^{145}$ To date, AM has been explored with numerous soft-magnetic materials and was recently reviewed. ${ }^{146-150}$ Thus, only a brief synopsis of the most recent AM studies on soft-magnetic alloys is provided in this review. Since the critical reviews published by Refs.146-150, a few additional studies on AM processing of soft-magnetic alloys have been published. One study by Koo et al. introduced a novel shell-shaping selective laser melting (SSSLM) approach to develop structurally layered Fe$\mathrm{Si}$ parts with a thin surface insulation coating between layers. ${ }^{151} \mathrm{Fe}-6.5 \mathrm{wt} . \% \mathrm{Si}$ powder was utilized in an SLM machine to construct specimens with internal shells aligned vertically from the build plate substrate. The internal shell thickness, analogous to rolled sheet thickness in conventional laminated cores, varied from $0.2 \mathrm{~mm}$ to $1 \mathrm{~mm}$. Samples were heat-treated and, in some cases, given a surface insulation coating $\left(\mathrm{SiO}_{2}\right)$ through a dipped sol-gel method. Both as-printed (cube specimens, Fig. 15) and annealed samples exhibited fullfield induction values approaching $1.68 \mathrm{~T}$ for uncoated samples. Coercivity decreased from $165 \mathrm{~A} / \mathrm{m}$ to $34.6 \mathrm{~A} / \mathrm{m}$ with increased annealing temperature, largely driven by grain growth effects. As expected, and like conventional sheet, core lose properties were shown to scale with interlayer shell size, exhibiting the lowest loss for the thinnest, 0.2 mm condition.

Andreiev et al. developed samples with varying cross-sectional area during SLM processing of $\mathrm{Fe}$ $3 \mathrm{wt} . \%$ Si alloy via predefined "slits" (empty regions without consolidated material) within the bulk geometry itself. ${ }^{152}$ Slit position and thickness were varied systematically. The authors concluded that continuous slits, i.e., those that were sufficiently wide to avoid powder consolidation within a given layer, led to the greatest power loss reduction when located near the outer surfaces of samples. The approach, while showing opportunities to tailor core loss properties, exhibited $\sim 5$ to 10 times more losses than conventional electrical steel alloys.

Nartu et al. evaluated structure-magnetic properties relationships of AM-processed Fe-Co-2V using the laser engineered net shaping (LENS) process. ${ }^{153}$ Samples were characterized both in the as-built condition and following one of two annealing treatments: (1) $950^{\circ} \mathrm{C}$ for $30 \mathrm{~min}$ with a water quench (single step), and (2) $950^{\circ} \mathrm{C}$ for 30 min with a second heat treatment at $500^{\circ} \mathrm{C}$ for $50 \mathrm{~h}$ followed by a water quench (two step). The two heat treatments isolated effects of annealing/residual stress and BCC-B2 phase transformations on magnetic properties. Grain structures were predominately equiaxed, with heat treatment leading to slight grain refinement due to recrystallization. As-deposited samples had higher full-field induction values compared with single-step annealed samples, 

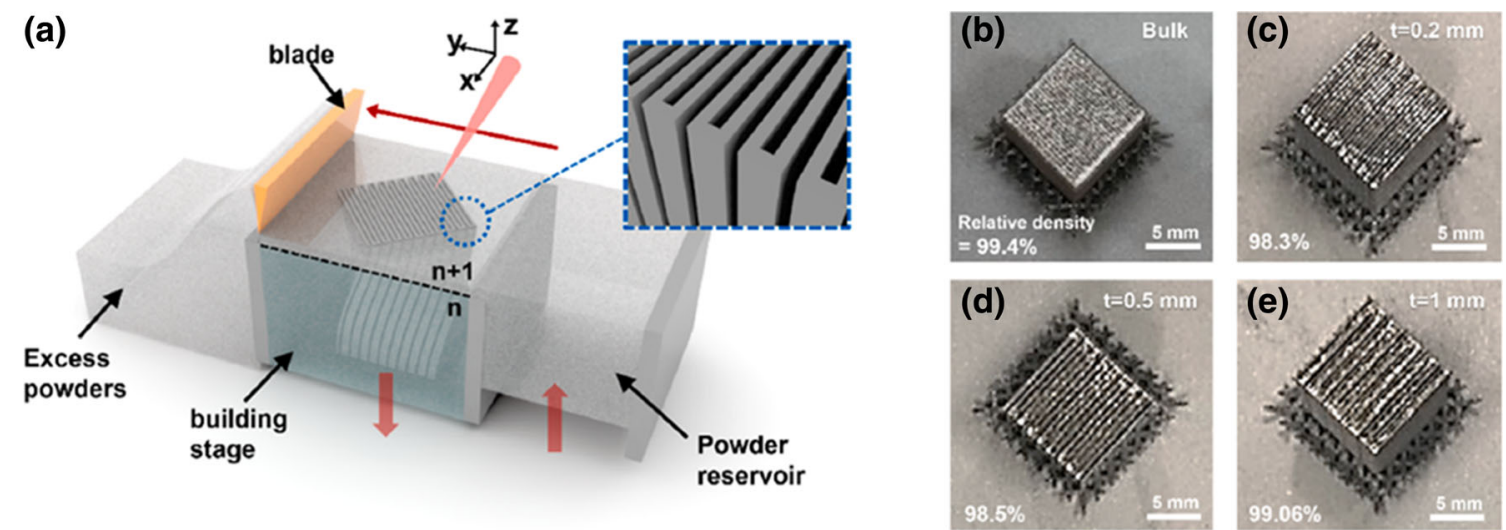

Fig. 15. Selective laser melting (a) of Fe-6.5 wt.\%Si samples to produce structurally layered soft-magnetic composites (b-e). Reprinted with permission from Elsevier: Ref. 151-B. Koo, M. S. Jang, Y. G. Nam, S. Yang, J. Yu, Y. H. Park, and J. W. Jeong, Structurally-layered soft magnetic Fe-Si components with surface insulation prepared by shell-shaping selective laser melting, Appl. Surf. Sci. 553, 149510 (2021).

while coercivity was generally in a similar range. The higher annealing temperatures led to an increase in retained austenite, reducing the softmagnetic properties. The two-step annealed samples had higher full-field induction and lower coercivity compared with as-deposited and single-step annealed materials. The authors related the improved magnetic softness for the two-step annealed material to larger antiphase domains and a greater extent of the chemically ordered B2 phase, which has been shown to drastically impact magnetic performance in other soft-magnetic alloys. ${ }^{5}$

AM represents an emerging and increasingly popular approach for producing bulk magnetic alloys due to the freedom in magnetic core design, the ability to process low-workability alloys and gradient alloys, and opportunities for tailoring grain structures and the extent of atomic ordering. These methods are continuing to be exploited for the development of novel soft-magnetic alloy structures for a wide range of electromagnetic applications.

\section{SUMMARY AND FUTURE OUTLOOK}

A review of unconventional and emerging manufacturing methods used to produce bulk soft-magnetic alloys is presented. Industrial production of bulk magnetic alloys was briefly discussed, being largely dominated by sheet and bar products. Principal categories of emerging manufacturing processes for soft-magnetic alloys were reviewed, including severe plastic deformation processes, powder-based methods, and recent efforts on additive manufacturing. These emerging processes offer differing but unique advantages and opportunities for producing bulk soft-magnetic alloys, often with unusual or tailored structure-composition-property relationships that cannot be replicated by conventional techniques. These advantages are particularly impactful for the production of bulk magnetic alloys that are too brittle or not practical for mainstream commercial processes. Continued development of these and other unconventional manufacturing methods is encouraged to address growing demands for higher-efficiency electromagnetic materials and devices.

While the unconventional manufacturing routes detailed in this review present opportunities for producing bulk forms of soft-magnetic alloys with tailored structure-property relationships, a majority of studies lack detailed characterization of mechanical properties, typically limited to microhardness measurements that provide an incomplete understanding of alloy performance. Additionally, studies survey a limited set of magnetic properties, with general emphasis on direct-current (DC) magnetic performance and isolated instances of alternating-current (AC) properties. As such, future studies that address these gaps in the field are recommended. Special attention is called to the following: (1) determination of detailed mechanical properties with benchmarks against conventionally processed material, targeting improvements in ductility without sacrificing magnetic performance, (2) characterization of magnetic anisotropy and sitespecific properties to elucidate the benefits afforded by these unconventional processes for imparting microstructural and/or compositional gradients, (3) extension to additional alloy systems and in particular emerging advanced alloys and composites within the complex concentrated alloy or highentropy alloy space, and (4) testing of integrated electromagnetic machine components with magnetic cores that are enabled by unconventional processing.

\section{ACKNOWLEDGEMENTS}

The authors thank Dr. Jessica Kustas and Dr. Deidre Hirschfeld for providing critical review of the manuscript. Funding support was provided through 
the Sandia National Laboratories Laboratory Directed Research and Development (LDRD) office. Sandia National Laboratories is a multimission laboratory managed and operated by National Technology and Engineering Solutions of Sandia LLC, a wholly owned subsidiary of Honeywell International Inc. for the US Department of Energy's National Nuclear Security Administration under Contract DE-NA0003525. This paper describes objective technical results and analysis. Any subjective views or opinions that might be expressed in the paper do not necessarily represent the views of the US Department of Energy or the US Government.

\section{CONFLICT OF INTEREST}

The authors declare that they have no conflicts of interest.

\section{OPEN ACCESS}

This article is licensed under a Creative Commons Attribution 4.0 International License, which permits use, sharing, adaptation, distribution and reproduction in any medium or format, as long as you give appropriate credit to the original author(s) and the source, provide a link to the Creative Commons licence, and indicate if changes were made. The images or other third party material in this article are included in the article's Creative Commons licence, unless indicated otherwise in a credit line to the material. If material is not included in the article's Creative Commons licence and your intended use is not permitted by statutory regulation or exceeds the permitted use, you will need to obtain permission directly from the copyright holder. To view a copy of this licence, visit $h$ ttp://creativecommons.org/licenses/by/4.0/.

\section{SUPPLEMENTARY INFORMATION}

The online version contains supplementary material available at https://doi.org/10.1007/s11837021-05019-9.

\section{REFERENCES}

1. B.D. Cullity and C.D. Graham, Introduction to Magnetic Materials, 2nd edn. (Wiley, Hoboken, New Jersey, 2009).

2. C. Chen, Magnetism and Metallurgy of Soft Magnetic Materials (Elsevier North-Holland Inc, New York, 1977).

3. N.P. Goss, Trans. ASM. 23, 511. (1935).

4. R. PremKumar, I. Samajdar, N.N. Viswanathan, V. Singal, and V. Seshadri, J. Magn. Magn. Mater. 264, 75. (2003).

5. T. Sourmail, Prog. Mater. Sci. 50, 816. (2005).

6. M. Ali and F. Ahmad, Mater. Manuf. Process. 34, 1580. (2019).

7. R.S. Sundar and S.C. Deevi, Int. Mater. Rev. 50, 157. (2005).

8. I. Husain, B. Ozpineci, M.S. Islam, E. Gurpinar, G.J. Su, W. Yu, S. Chowdhury, L. Xue, D. Rahman, and R. Sahu, Proc. IEEE 109, 1039. (2021).

9. I. Baker, Mater. Sci. Eng. A 192-193, 1. (1995).
10. A.H. Kasama, C. Bolfarini, C.S. Kiminami, and W.J. Botta Filho, Mater Sci. Eng. A 449-451, 375. (2007).

11. G. Ouyang, X. Chen, Y. Liang, C. Macziewski, and J. Cui, J. Magn. Magn. Mater. 481, 234. (2019).

12. D.W. Clegg and R.A. Buckley, Met. Sci. J. 7, 48. (1973).

13. G. Ouyang, C.R. Macziewski, B. Jensen, T. Ma, R. Choudhary, K. Dennis, L. Zhou, D. Paudyal, I. Anderson, M.J. Kramer, and J. Cui, Acta Mater. 205, 116575. (2021).

14. K. Kawahara, J. Mater. Sci. 18, 1709. (1983).

15. O. Gutfleisch, M.A. Willard, E. Brück, C.H. Chen, S.G. Sankar, and J.P. Liu, Adv. Mater. 23, 821. (2011).

16. A.T.S. Subramanian, P. Meenalochini, S.S.B. Sathiya, and G.R. Prakash, Mater. Today Proc. 45, 1591. (2021).

17. M.E. McHenry, M.A. Willard, and D.E. Laughlin, Prog. Mater. Sci. 44, 291. (1999).

18. M. Cockcroft and D. Latham, J Inst Met. 96, 33. (1968).

19. A. Kordecki, B. Węliński, and J. Kaczmar, Powder Metall. 25, 201. (1982).

20. A.B. Kustas, D. Sagapuram, K.P. Trumble, and S. Chandrasekar, Metall. Mater. Trans. A Phys. Metall. Mater. Sci. 47, 3095. (2016).

21. JFE Steel Corporation Datasheet, SuperCore Electrical Steel Sheets for High-Frequency Application (2017).

22. F. Fiorillo, G. Bertotti, C. Appino, and M. Pasquale, Wiley Encycl. Electr. Electron. Eng. 1 (2016).

23. R.M. Bozorth, Ferromagnetism (Van Nostrand, New York, 1951).

24. S. Kasai, M. Namikawa, and T. Hiratani, JFE Tech. Rep. 21, 14. (2016).

25. T. Doi and H. Ninomiya, in Conference on Proceedings-Twenty-Seventh Annunal IEEE Applied Power Electronronics Conference Expo.-APEC (IEEE, 2012), pp. 1740-1746.

26. R. Li, Q. Shen, L. Zhang, and T. Zhang, J. Magn. Magn. Mater. 281, 135. (2004).

27. G.D. Lahoti and P.M. Pauskar, in ASM Handbook. Vol. 14 Metalwork. Bulk Form., edited by S. L. Semiatin (ASM International, Materials Park, 2005), pp. 459-479.

28. H.W. Sizek, in ASM Handbook Vol. 14 Metalwork. Bulk Form., edited by S. L. Semiatin (ASM International, Materials Park, 2005), pp. 172-178.

29. D.F. Susan, T. Jozaghi, I. Karaman, and J.M. Rodelas, J. Mater. Res. 33, 2176. (2018).

30. R.Z. Valiev, R.K. Islamgaliev, and I.V. Alexandrov, Prog. Mater. Sci. 45, 103. (2000).

31. L. De Chiffre, Int. J. Mach. Tool Des. Res. 16, 137. (1976).

32. W. Moscoso, M.R. Shankar, J.B. Mann, W.D. Compton, and S. Chandrasekar, J. Mater. Res. 22, 201. (2007).

33. M. Efe, W. Moscoso, K.P. Trumble, W. Dale Compton, and S. Chandrasekar, Acta Mater. 60, 2031. (2012).

34. D. Sagapuram, M. Efe, W. Moscoso, S. Chandrasekar, and K.P. Trumble, Acta Mater. 61, 6843. (2013).

35. A. Kustas, K. Chaput, S. Chandrasekar, and K. Trumble, in Material Science Technology Conference Exhibition 2014, MS T 2014 (2014), pp. 1-8.

36. M.N. Issahaq, S. Chandrasekar, and K.P. Trumble, J. Manuf. Sci. Eng. Trans. ASME 143, 1. (2021).

37. P. Iglesias, M.D. Bermúdez, W. Moscoso, and S. Chandrasekar, Wear 268, 178. (2010).

38. D. Sagapuram, A. B. Kustas, W. Dale Compton, K. P. Trumble, and S. Chandrasekar, 137, 1 (2015).

39. P. Iglesias, M.D. Bermúdez, W. Moscoso, B.C. Rao, M.R Shankar, and S. Chandrasekar, Wear 263, 636. (2007).

40. S. Mishra, C. Därmann, and K. Lücke, Acta Metall. 32, 2185. (1984).

41. A.B. Kustas, S. Chandrasekar, and K.P. Trumble, J. Mater. Res. 31, 3930. (2016).

42. AK Steel Corporation Product Data Bulletin, DI-MAX HF 10X COLD ROLLED FULLY PROCESSED Non-Oriented Electrical Steel Material (2018).

43. A.B. Kustas, D.R. Johnson, K.P. Trumble, and S. Chandrasekar, J. Mater. Process. Technol. 257, 155. (2018).

44. I.J. Beyerlein and L.S. Tóth, Prog. Mater. Sci. 54, 427. (2009). 
45. V.M. Segal, Mater. Sci. Eng. A 197, 157. (1995).

46. I. Karaman, A.V. Kulkarni, and Z.P. Luo, Philos. Mag. 85, 1729. (2005).

47. M. F. Gigliotti, R. DiDomizio, L. E. Iorio, F. Johnson, P. R. Subramanian, and M. Chandran, US Patent No. 7,905,965 B2 (2011).

48. L. Weißner, T. Gröb, E. Bruder, P. Groche, and C. Müller, Appl. Mech. Mater. 794, 152. (2015).

49. A.I. Korshunov, N.I. Osipova, A.M. Olenin, Y.N. Pigarev, and O.V. Kulakova, Phys. Met. Metallogr. 119, 448. (2018).

50. Carpenter Technology Technical Datasheet, Hiperco ${ }^{\circledR} 27$ (2020).

51. L.Z. Wu, J. Chen, Z.Z. Du, and J.T. Wang, Trans. Nonferrous Met. Soc. China English Ed. 20, 602. (2010).

52. D. Zhong-ze, W. Lai-zhi, F. Han-guang, W. Qing-juan, and W. Jing-tao, Trans. Mat. Heat Treat. 29, 47. (2008).

53. A.B. Kustas, J.R. Michael, D.F. Susan, I. Karaman, and T. Jozaghi, J. Mater. Res. 33, 2176. (2018).

54. D.F. Susan, A.B. Kustas, R.A. Kellogg, J.D. Carroll, J.R. Michael, and I. Karaman, Metall. Mater. Trans. A 52A, 4090. (2021)

55. Carpenter Technology Technical Datasheet, CarTech ${ }^{\circledR}$ Hiperco ${ }^{\circledR} 50$ A Alloy (2017).

56. N.S. Stoloff and I.L. Dillamore, in Proceedings of the Third Bolt Land Conference (Claitor's Publishing Division, 1970), p. 525.

57. E.P. George, A.N. Gubbi, I. Baker, and L. Robertson, $M a-$ ter. Sci. Eng. A 329-331, 325. (2002).

58. C.D. Pitt and R.D. Rawlings, Met. Sci. 17, 261. (1983).

59. D.R. Thornburg, J. Appl. Phys. 40, 1579. (1969).

60. R.H. Yu, S. Basu, Y. Zhang, A. Parvizi-Majidi, and J.Q. Xiao, J. Appl. Phys. 85, 6655. (1999).

61. D. Gautard, G. Couderchon, and L. Coutu, J. Magn. Magn. Mater. 160, 359. (1996).

62. S. Liu, S. Bauser, Z. Turgut, J. Coate, and R.T. Fingers, J. Appl. Phys. 93, 7118. (2003).

63. R.V. Major and V. Samadian, J. Mater. Eng. 11, 27. (1989).

64. R.D. Rawlings, R. V. Major, and C. M. Orrock, US Patent No. 4,933,026 (1990).

65. P.W. Bridgman, J. Appl. Phys. 14, 273. (1943).

66. A.P. Zhilyaev and T.G. Langdon, Prog. Mater. Sci. 53, 893. (2008).

67. A. Vorhauer, K. Rumpf, P. Granitzer, S. Kleber, H. Krenn, and R. Pippan, Mater. Sci. Forum 503-504, 299. (2006).

68. S. Scheriau, K. Rumpf, S. Kleber, and R. Pippan, Mater. Sci. Forum 584-586 PA, 923 (2008).

69. S. Scheriau, M. Kriegisch, S. Kleber, N. Mehboob, R. Grssinger, and R. Pippan, J. Magn. Magn. Mater. 322, 2984. (2010).

70. G. Herzer, IEEE Trans. Magn. 26, 1397. (1990).

71. A.M. Glezer, M.P. Plotnikova, A.V. Shalimova, and N.S. Perov, Bull. Russ. Acad. Sci. Phys. 73, 1240. (2009).

72. A.M. Glezer, A.A. Tomchuk, A.G. Savchenko, V.V. Korovushkin, and I.V. Shchetinin, Bull. Russ. Acad. Sci. Phys. 80, 1021. (2016).

73. I.A. Glezer, I.V. Timshin, M.V. Shchetinin, R.V. Gorshenkov, A. Sundeev, and G. Ezhova, J. Alloys Compd. 744, 791. (2018)

74. A.M. Glezer, M.A. Libman, I.A. Timshin, I.V. Shchetinin, E.S. Savchenko, and A.A. Tomchuk, JETP Lett. 108, 54. (2018).

75. A.M. Glezer, L.F. Muradimova, S.O. Shirshikov, I.V. Shchetinin, and D'yakonov DL, Tomchuk AA, Bull. Russ. Acad. Sci. Phys. 83, 1250. (2019).

76. A.M. Glezer, L.F. Muradimova, P.A. Borisova, A.A. Veligzhanin, O.V. Chernysheva, R.V. Sundeev, D.V. Louzguine-Luzgin, N.S. Perov, S. Shirshikov, and O. Tomchuk, J. Alloys Compd. 866, 159021. (2021).

77. G. Abrosimova, A. Aronin, D. Matveev, and E. Pershina, Mater. Lett. 97, 15. (2013).

78. A. Aronin, G. Abrosimova, D. Matveev, and O. Rybchenko, Rev. Adv. Mater. Sci. 25, 52. (2010).

79. A. Hosokawa, H. Ohtsuka, T. Li, S. Ii, and K. Tsuchiya, Mater. Trans. 55, 1286. (2014).
80. M. Stückler, L. Weissitsch, S. Wurster, H. Krenn, R. Pippan, and A. Bachmaier, J. Mater. Res. Technol. 12, 1235. (2021).

81. Y. Saito, H. Utsunomiya, N. Tsuji, and T. Sakai, Acta Mater. 47, 579. (1999).

82. N. Tsuji, Y. Saito, S.H. Lee, and Y. Minamino, Adv. Eng. Mater. 5, 338. (2003).

83. A.H. Eslami, S. Mojtaba Zebarjad, and M.M. Moshksar, Mater Sci. Technol. (United Kingdom) 29, 1000. (2013).

84. F. Daneshvar, M. Reihanian, and K. Gheisari, Mater. Sci. Eng. B Solid-State Mater. Adv. Technol. 206, 45. (2016).

85. L. Zhang, W. Wang, X. Xiao, M. Babar Shahzad, Y. Shan, and K. Yang, Acta Metall. Sin. English Lett. 33, 385. (2020).

86. Y. Zhu, Z. Li, Z. Xiao, W. Qiu, M. Fang, and Z. Chen, Mater. Charact. 163, 110290. (2020).

87. J.M. Silveyra, E. Ferrara, D.L. Huber, and T.C. Monson, Science 362(80), 1. (2018).

88. R. Hasegawa, J. Magn. Magn. Mater. 304, 187. (2006).

89. G. Herzer, Acta Mater. 61, 718. (2013).

90. A. Talaat, M.V. Suraj, K. Byerly, A. Wang, Y. Wang, J.K. Lee, and P.R. Ohodnicki, J. Alloys Compd. 870, 159500. (2021).

91. P. Duwez and S.C.H. Lin, J. Appl. Phys. 38, 4096. (1967).

92. Y. Yoshizawa, S. Oguma, and K. Yamauchi, J. Appl. Phys. 6044, 7. (2017).

93. A. Makino, A. Inoue, and T. Masumoto, Mater. Trans. 36, 924. (1995)

94. E. Theisen, MRS Adv. 2, 3409. (2017).

95. M.A. Willard, D.E. Laughlin, M.E. McHenry, D. Thoma, K. Sickafus, J.O. Cross, and V.G. Harris, J. Appl. Phys. 107 (1998).

96. H. Zheng, L. Zhu, S.S. Jiang, Y.G. Wang, S.N. Liu, S. Lan, and F.G. Chen, J. Alloys Compd. 816, 152549. (2020).

97. Z. Li, R. Parsons, B. Zang, H. Kishimoto, T. Shoji, A. Kato, J. Karel, and K. Suzuki, Scr. Mater. 181, 82. (2020).

98. K.G. Pradeep, G. Herzer, P. Choi, and D. Raabe, Acta Mater. 68, 295. (2014).

99. G. Ouyang, B. Jensen, W. Tang, J. Schlagel, B. Hilliard, C. Pan, B. Cui, K. Dennis, D. Jiles, T. Monson, I. Anderson, M.J. Kramer, and J. Cui, Acta Mater. 201, 209. (2020).

100. R. Hamzaoui and O. Elkedim, J. Alloys Compd. 573, 157. (2013).

101. J.E. Garay, Annu. Rev. Mater. Res. 40, 445. (2010).

102. R. Orrù, R. Licheri, A.M. Locci, A. Cincotti, and G. Cao, Mater. Sci. Eng. R Rep. 63, 127. (2009).

103. Z.A. Munir, U. Anselmi-Tamburini, and M. Ohyanagi, J. Mater. Sci. 41, 763. (2006).

104. N. Saheb, Z. Iqbal, A. Khalil, A. S. Hakeem, N. Al Aqeeli, T. Laoui, A. Al-Qutub, and R. Kirchner, J. Nanomater. 2012, 1 (2012).

105. M. Yue, J. Zhang, M. Tian, and X.B. Liu, J. Appl. Phys. 99 , 08B502. (2006)

106. Y. Do Kim, J.Y. Chung, J. Kim, and H. Jeon, Mater. Sci. Eng. A 291, 17. (2000).

107. J.R. Morales, J.E. Garay, M. Biasini, and W.P. Beyermann, Appl. Phys. Lett. 93, 22511. (2008).

108. J.R. Morales, S. Tanju, W.P. Beyermann, and J.E. Garay, Appl. Phys. Lett. 96, 13102. (2010)

109. C. Fei, Y. Zhang, Z. Yang, Y. Liu, R. Xiong, J. Shi, and X. Ruan, J. Magn. Magn. Mater. 323, 1811. (2011).

110. T. Gheiratmand, H.R. Madaah Hosseini, and S.M. Seyed Reihani, J. Magn. Magn. Mater. 429, 241. (2017).

111. V. Chaudhary, L.P. Tan, V.K. Sharma, and R.V. Ramanujan, J. Alloys Compd. 869, 159318. (2021).

112. Z. Fu, B.E. MacDonald, A.D. Dupuy, X. Wang, T.C. Monson, R.E. Delaney, C.J. Pearce, K. Hu, Z. Jiang, Y. Zhou, J.M. Schoenung, W. Chen, and E.J. Lavernia, Appl. Mater. Today 15, 590. (2019)

113. U. Anselmi-Tamburini, S. Gennari, J.E. Garay, and Z.A. Munir, Mater. Sci. Eng. A 394, 139. (2005).

114. Z.A. Munir, D.V. Quach, and M. Ohyanagi, J. Am. Ceram. Soc. 94, 1. (2011).

115. J. Merhar, Met. Powder Rep. 45, 339. (1990). 
116. I. Todd and A. T. Sidambe, in Adv. Powder Metall., edited by I. Chang and Y. Zhao (Elsevier, Cambridge, 2013), pp. 109-146.

117. D.A. Barrow, Mater. Des. 9, 345. (1988).

118. H. Miura, M. Yonetsu, M. Nakai, and Y. Kawakami, J. Jpn. Soc. Powder Powder Metall. 43, 858. (1996).

119. H. Miura, M. Yonetsu, and J. Nuka, Funtai Oyobi Fummatsu Yakin/Journal Japan Soc Powder Powder Metall. 46, 858. (1999).

120. H. Miura and H. Kang, Powder Metall. 56, 38. (2013).

121. J. Ma, M. Qin, L. Zhang, R. Zhang, L. Tian, X. Zhang, and X. Qu, Mater. Chem. Phys. 138, 444. (2013).

122. J. Ma, M. Qin, L. Zhang, R. Zhang, L. Tian, X. Zhang, X. Li, X. Qu, and D.F. Khan, Mater. Des. 51, 1018. (2013).

123. R.M. Bozorth, Rev. Mod. Phys. 25, 42. (1953).

124. J. Ma, M. Qin, L. Tian, L. Zhang, D.F. Khan, X. Ding, X. $\mathrm{Qu}$, and H. Zhang, J. Magn. Magn. Mater. 397, 240. (2016).

125. A. Páez-Pavón, A. Jiménez-Morales, T.G. Santos, L. Quintino, and J.M. Torralba, J. Magn. Magn. Mater. 416, 342. (2016).

126. A. Páez-Pavón, A. Jiménez-Morales, M. Rodriguez-Arbaizar, E. Carreño-Morelli, and J.M. Torralba, Powder Metall. 60, 112. (2017).

127. Y. Zhang, R. Ma, S. Feng, L. Cheng, P.A. Davies, and P. Yu, J. Magn. Magn. Mater. 497, 165982. (2020).

128. J. R. Davis, in Handbook Thermal Spray Technology, edited by J. R. Davis (ASM International, Materials Park, OH, 2004), pp. 3-4.

129. T. Suhonen, T. Varis, S. Dosta, M. Torrell, and J.M. Guilemany, Acta Mater. 61, 6329. (2013).

130. J. Li, J.P. Longtin, S. Tankiewicz, A. Gouldstone, and S. Sampath, Sens. Actuat. A Phys. 133, 1. (2007).

131. P. Alkimov, V.F. Kosarev, and A.N. Papyrin, Sov. Phys. Dokl. 35, 1047. (1990)

132. R.C. Dykhuizen and M.F. Smith, J. Therm. Spray Technol. 7, 205. (1998)

133. R.C. Dykhuizen, M.F. Smith, D.L. Gilmore, R.A. Neiser, X. Jiang, and S. Sampath, J. Therm. Spray Technol. 8, 559. (1999).

134. A. H. Kasama, A. Moreira, W. J. B. F. W.J.B., C. S. Kiminami, and C. Bolfarini, Mater. Sci. Eng. A. 477, 9 (2008).

135. S. Sampath, J. Therm. Spray Technol. 19, 921. (2010).

136. F.T. Parker, F.E. Spada, A.E. Berkowitz, K.S. Vecchio, E.J. Lavernia, and R. Rodriguez, Mater. Lett. 48, 184. (2001).
137. M. Cherigui, Z. Salhi, N.E. Fenineche, P. Gougeon, and C. Coddet, Mater. Lett. 59, 463. (2005).

138. M. Cherigui, N.E. Fenineche, and C. Coddet, Surf. Coat Technol. 192, 19. (2005).

139. M. Cherigui, N.E. Fenineche, G. Ji, T. Grosdidier, and C. Coddet, J. Alloys Compd. 427, 281. (2007).

140. W.Y. Li and C.J. Li, Appl. Surf. Sci. 256, 2193. (2010).

141. T. Van Steenkiste, Proc. Int. Therm. Spray Conf. 15, 501. (2006).

142. M. Cherigui, W. Li, R. Hamzaoui, V. Ji, N. Fenineche, and C. Coddet, Eur. Phys. J. Appl. Phys. 43, 79. (2008).

143. P.C. King, S.H. Zahiri, and M.Z. Jahedi, J. Therm. Spray Technol. 17, 221. (2008).

144. J.M. Lamarre and F. Bernier, J. Therm. Spray Technol. 28, 1709. (2019)

145. B.H. Jared, M.A. Aguilo, L.L. Beghini, B.L. Boyce, B.W Clark, A. Cook, B.J. Kaehr, and J. Robbins, Scr. Mater. 135, 141. (2017)

146. E.A. Périgo, J. Jacimovic, F. García Ferré, and L.M. Scherf, Addit. Manuf. 30, 100870. (2019).

147. V. Chaudhary, S.A. Mantri, R.V. Ramanujan, and R. Banerjee, Prog. Mater. Sci. 114, 100688. (2020).

148. T.N. Lamichhane, L. Sethuraman, A. Dalagan, H. Wang, J. Keller, and M.P. Paranthaman, Mater. Today Phys. 15, 100255. (2020).

149. T. Pham, P. Kwon, and S. Foster, Energies 14, 283. (2021).

150. D. Goll, D. Schuller, G. Martinek, T. Kunert, J. Schurr, C. Sinz, T. Schubert, T. Bernthaler, H. Riegel, and G. Schneider, Addit. Manuf. 27, 428. (2019).

151. B. Koo, M.S. Jang, Y.G. Nam, S. Yang, J. Yu, Y.H. Park, and J.W. Jeong, Appl. Surf. Sci. 553, 149510. (2021).

152. A. Andreiev, K.P. Hoyer, D. Dula, F. Hengsbach, M. Haase, J. Gierse, D. Zimmer, T. Tröster, and M. Schaper, J. Mater. Process. Technol. 296, 117183. (2021)

153. M.S.K.K.Y. Nartu, S. Dasari, A. Sharma, V. Chaudhary, S.M. Varahabhatla, S.A. Mantri, E. Ivanov, R.V. Ramanujan, N.B. Dahotre, and R. Banerjee, J. Alloys Compd. 861, 157998. (2021).

Publisher's Note Springer Nature remains neutral with regard to jurisdictional claims in published maps and institutional affiliations. 